$$
\begin{aligned}
& \text { المخاطر الاجتماعية والأمنية لمو اقع التواصل الاجتماعي } \\
& \text { على عينة من الطلاب بجامعة جنوب الوادي ادي بقنا }
\end{aligned}
$$

د. إيمان سيد عبد الحكيم

مدرس علم المكتبات والمعلومات

كلية الآداب - جامعة جنوب الوادي

المستخلص:

هدفت الدراسة إلي التعرف على المخاطر الأمنية والاجتماعية لمواقع التواصل

الاجتماعي على الطلاب بجامعة جنوب الوادي بقنا، بهدف تجنب تلك المخاطر وتحقيق

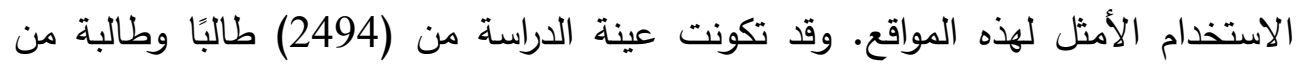

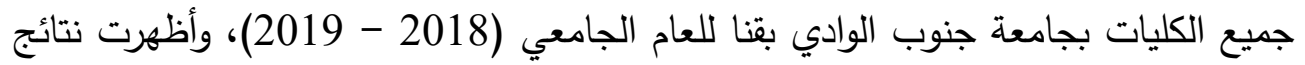

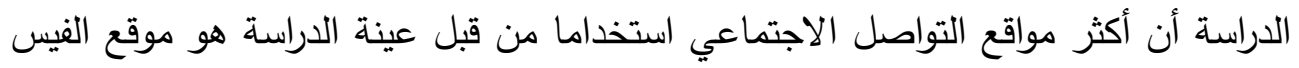
بوك بنسبة مئوية بلغت 68,8\% كما توصلت الدراسة إلى أن أكثر المخاطر الأمنية لمواقع مونع

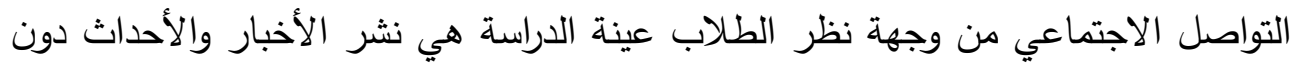
التأكد من صحتها بنسبة بلغت 54,3\%، وتؤثر مواقع التواصل الاجتماعي فكريا على هلى هينه

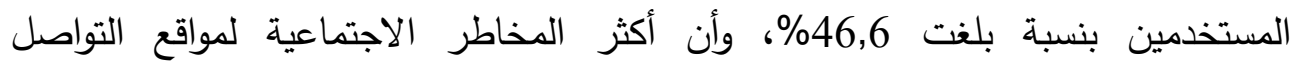
الاجتماعي من وجهة نظر الطلاب عينة الدراسة تتلخص في سيطرة الأوهام على الحقيقة ونشر الرزيلة بين الثباب بنسبة بلغت 35,4\% وترويج الثقافة الغربية في البلاد العربية بنسبة بلغت 40,4\%، لذا أوصت الدراسة بضرورة التوعية من قبل الجامعة من خلال مقرر

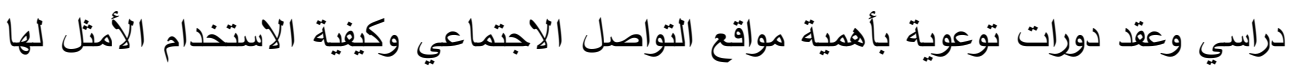

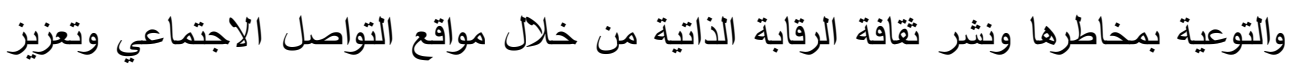
الوازع الديني لاى الثباب ووضع قواعد وضوابط من خلال الوسائل التكنولوجية الحديثة لمراقبة المواقع الممنوعة والتوعية بالاستخدام الرشيد المعتدل لمواقع التواصل الاجتماعي.

\title{
الكعلمات المفتاحية:
}

مواقع التواصل الاجتماعي - المخاطر الأمنية - المخاطر الاجتماعية - طلاب 


\section{مقدمة:}

أدى التقدم الهائل في تكنولوجيا الاتصال إلي إنتاج وسائل اتصال جديدة عملت

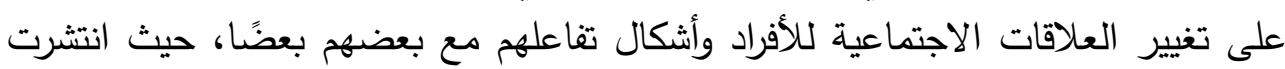

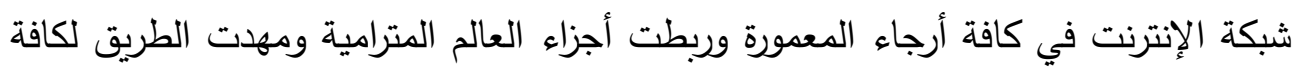
المجتمعات للتقارب والتعارف وتبادل الآراء والأفكار والرغبات، من خلال مواقع التواصل التصل

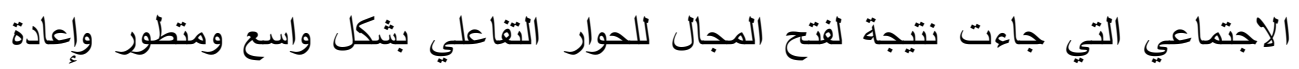
العلاقات بين الأفراد سواء كانوا زملاء مدرسة أو جامعة أو لهم صلة ما ببعضهمه ل (بوسحلة،

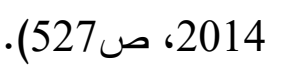

ومع انتشار وسائل التواصل الاجتماعي بشكل كبير في الآونة الأخيرة أصبحت هي الوسيلة الوحيدة التي فرضت سيطرتها على المجتمع وأصبح مستخدموها يتجاوزون المليارات وأصبحت وسيلة شديدة التأثير على المجتمعات بشكل كبير وخطير؛ ذلك لوسئ لأنها تستخدم

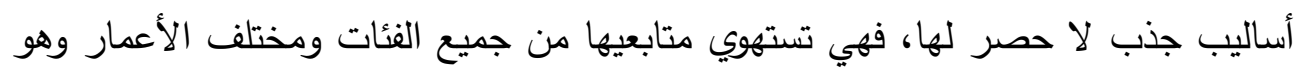

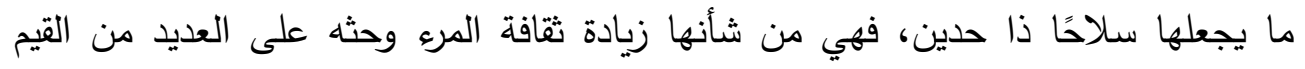

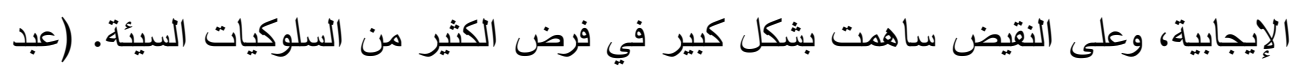

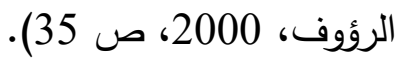

ولأن مواقع التواصل الاجتماعي دخلت اليوم جميع البيوت دون استئذان وأصبح

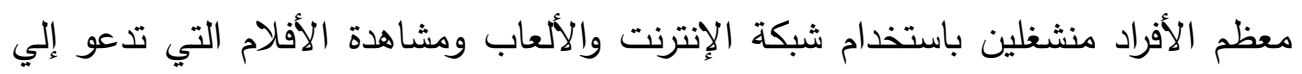
العنف وقضاء معظم أوقاتهم خلف شاشات الحاسوب أو الهاتف للولوج إلى مواقع التواصل

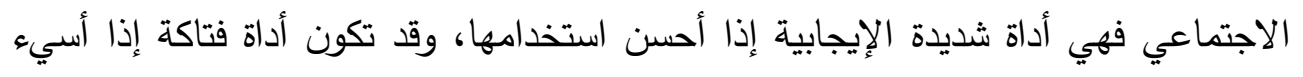
استخدامها مما ينعكس بالسلب على القيم التي تغرس بداخلهم وتغير فكرهم وتعمل على التى

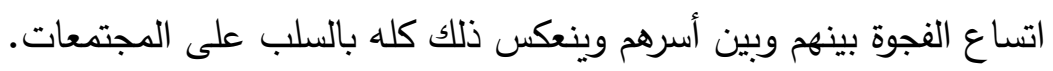
لقد فتحت شبكة الإنترنت الباب أمام تدفق المعلومات وراح عشاقها ينعزلون شئيًا فشييًا عن محيطهم الاجتماعي وتحولوا إلى موسوعة معلومات تجهل أبسط سبل الاتصال الإنساني

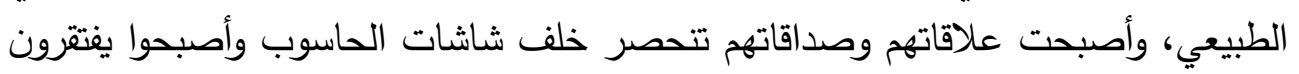
إلى الاحتكاك المباشر مع عامة الناس، فبات من الواضح أن الثبكة العالمية بدأت تكثف وأف

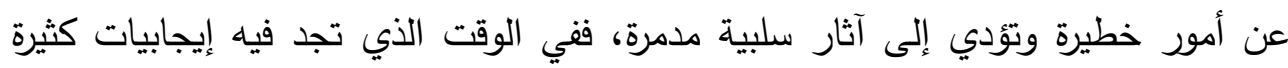

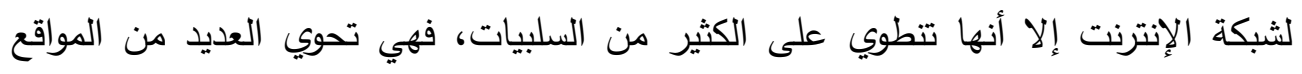

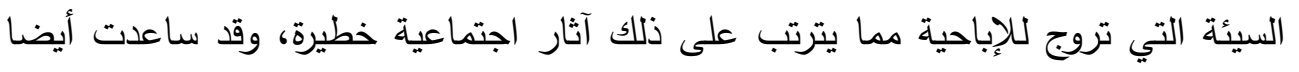


على عولمة الجريمة حيث أتاحت للمجرمين فرصة ممارسة نشاطاتهم الإجرامية على نطاق أوسع بعد أن كانت محصورة سابقا داخل نطاق الدولة التي يعيشون فيها.(الطراونة والفنيخ،

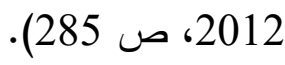

وتشهد استخدامات شبكات التواصل الاجتماعي مثل الفيس بوك وتويتر واليوتيوب

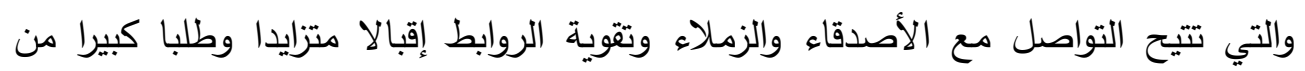

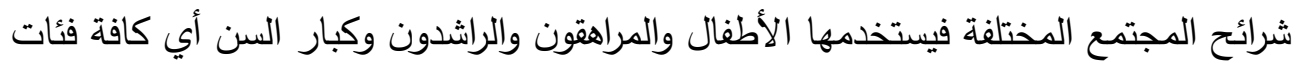

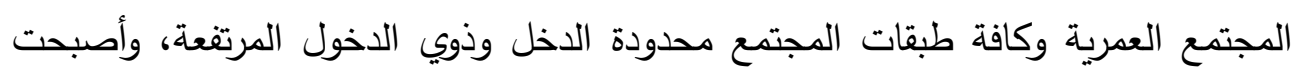

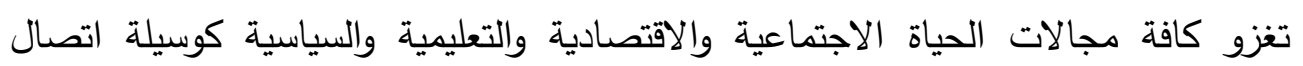
وتبادل الأفكار والمعلومات. (عبد المنعم والطاهر وغريب، ص 276 - 277)

وفي الوقت الذي زادت فيه شعبية المواقع الاجتماعية بمستويات مذهلة وفوائدها

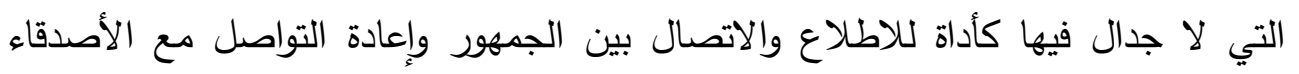

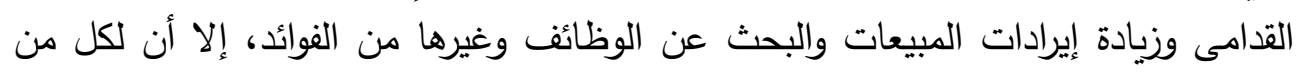

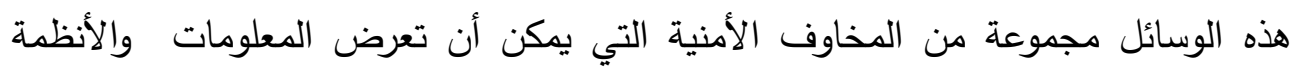
والبيانات الشخصية للخطر . (Dinerman, 2011, p3).

وتشير بعض الدراسات إلي أن مخاطر الإنترنت يمكن تجميعها في ثلاث فئات

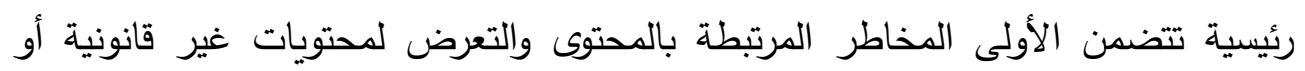
ضارة، أما الثانية فتتعلق بمخاطر الخصوصية والأمن وقد يكون واضحًا بشكل كبير في

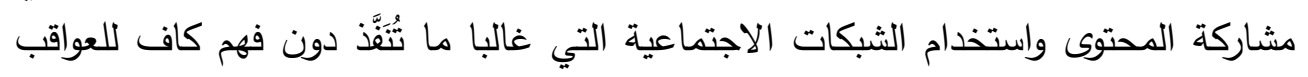

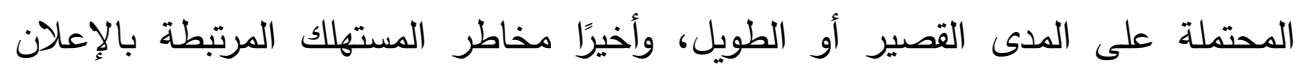

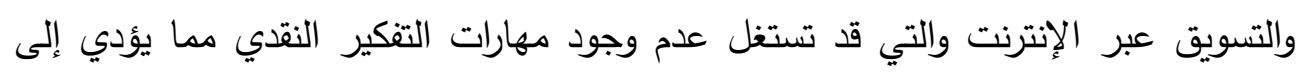

زيادة الإنفاق والمعاملات الاحتيالية. (Eysenbach 2017).

وبعد أن أصبحت وسائل التواصل الاجتماعي أكثر انتشارًا بين المراهقين، تطورت

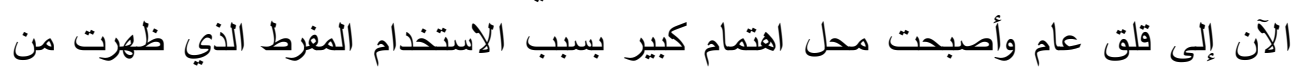

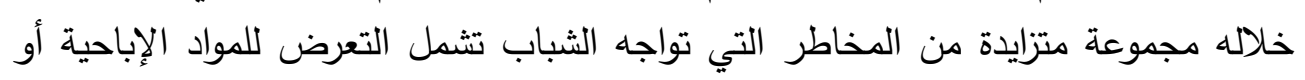
المواد العنيفة واستهدافهم للمضايقات والتسلط عبر الإنترنت والاستجداء الجنسي وإدمان الإنترنت.) (Leung , 2014

وانطلاقا من الآثار التي فرضتها علينا مواقع التواصل الاجتماعي ودورها في إحداث التغيير في كل جوانب المجتمع، تأتي هذه الدراسة للوقوف على الطى المخاطر الأمنية 
والاجتماعية لمواقع التواصل الاجتماعي التي تهدد المجتمع وخصوصًا فئة الشباب الأكثر استخداما لتلك المواقع متمثلة في طلاب الجامعة، حتى يمكن الخروج بنتائج تساعدنا في

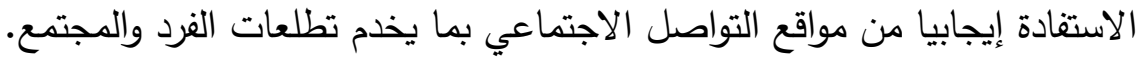

\section{مشكلة الدراسة:}

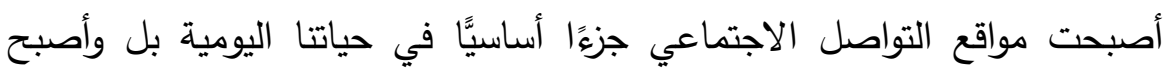

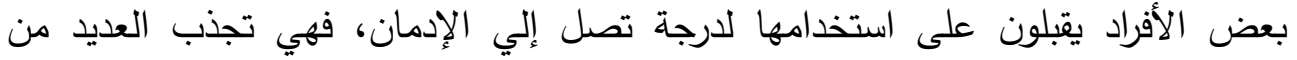
الفئات العمرية خصوصًا الثباب وتزداد نسبة انتشارها بين الطلاب الجامعيين وهم الفئة

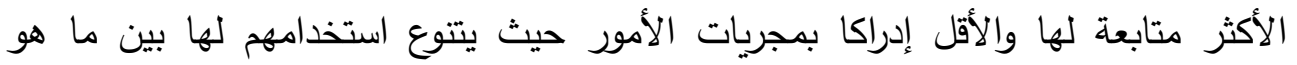
إيجابي وما هو سلبي.

فقد أصبحت مواقع التواصل الاجتماعي اليوم من المؤسسات المهمة التي تقوم بدور

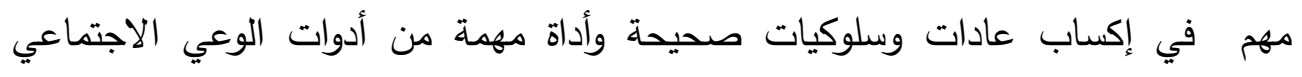
والسياسي والثقافي وذلك بقصد الاستفادة من إشغال وقت الشباب بما يفيدهم وزرع جوانب الثبات

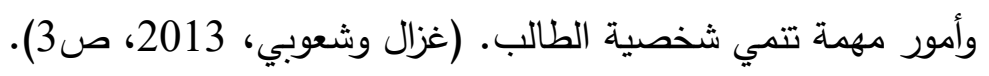

وعلى الرغم من الفوائد الجمة لمواقع التواصل الاجتماعي، إلا أنها في الوقت نفسه

تحوي العديد من المخاطر التي تتذر بحدوث تغييرات كبيرة في العلاقات الاجتماعية والقيم

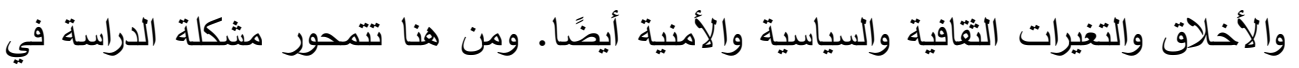
التساؤل التالي: ما المخاطر الاجتماعية والأمنية لمواقع التواصل الاجتماعي ولية على طلاب

\section{أهمية الاراسةة:}

تستمد هذه الدراسة أهميتها من أهمية مواقع التواصل الاجتماعي التي انتشرت

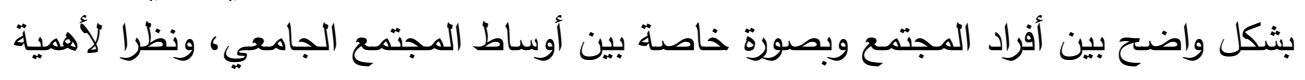
فئة الطلبة الجامعيين فهذه الفئة تعد طاقة بشرية مهمة ومؤثرة في كيان المجتمع تحتاج للاهتمام والمحافظة عليها ، لذا كان لا بد من الوقوف على المخاطر الألى الاجتماعية والأمنية لتلك المواقع وتأثيرها على الثباب الجامعي. لماني. 
د. إيمان سيد عبد الحكيم

كما تكمن أهمية الدراسة في ندرة الدراسات التي تتاولت مخاطر مواقع التواصل الاجتماعي على طلاب جامعة جنوب الوادي بقنا، ومن ثم قد تساعد هذه الدراسة المؤسسات

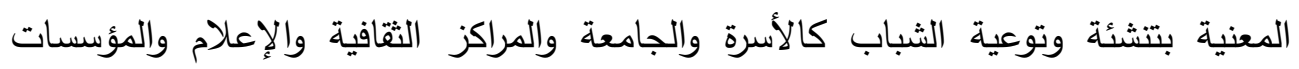

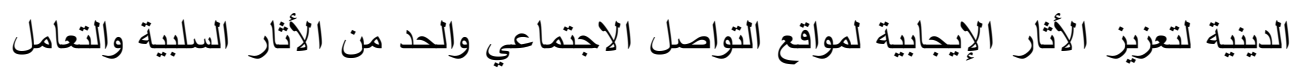
الإيجابي السليم مع تلك المواقع.

أهداف الدراسةة:

تسعى الاراسة إلى تحقيق الأهداف الآتية:

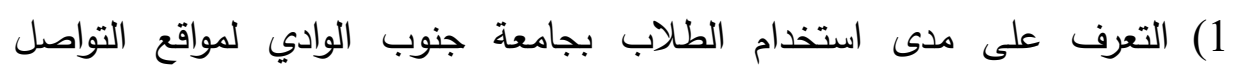
الاجتماعي وطبيعة الأجهزة المستخدمة كوسيلة للاتصال بتلك المواقع.

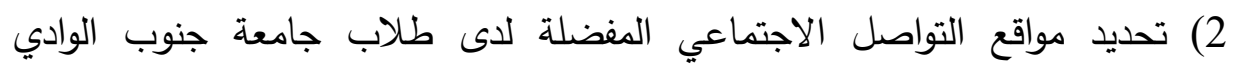
والأكثر استخداما لديهم.

3) تحديد معدل تكرار الدخول على مواقع التواصل الاجتماعي وعدد ساعات التصفح يوميا والطرق المستخدمة في التواصل مع الآخرين.

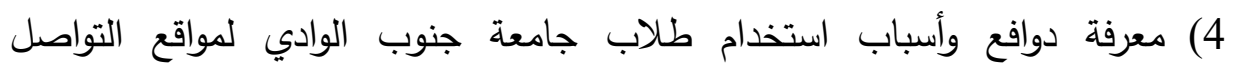
الاجتماعي.

5) الوقوف على الموضوعات التي يفضل طلاب جامعة جنوب الوادي الاطلاع عليها عبر مواقع التواصل الاجتماعي. 6) الكثف عن الجانب السلبي الذي تؤثر عليه مواقع التواصل الاجتماعي من وجهة نظر الطلاب بجامعة جنوب الوادي. 7) تحديد المخاطر الاجتماعية لمواقع التواصل الاجتماعي على لودئ طلاب جامعة جنوب الوادي.

8) تحديد المخاطر الأمنية لمواقع التواصل الاجتماعي على طلاب جامعة جنوب المب الوادي.

9) التعرف على مقترحات عينة الدراسة لتقليص الآثار السلبية لمواقع التواصل الاجتماعي. 


\section{تساؤلات الدراسة:}

1) ما مدى استخدام الطلاب بجامعة جنوب الوادي لمواقع التواصل الاجتماعي وما طبيعة

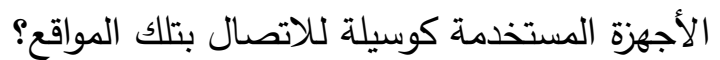
2) ما مواقع التواصل الاجتماعي المفضلة لدى طلاب جامعة جنوب الوادي والأكثر

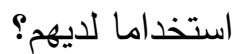
3) ما معدل تكرار الدخول على مواقع التواصل الاجتماعي وما عدد ساعات التصفح يوميا وما الطرق المستخدمة في التواصل مع مع الآخرين؟

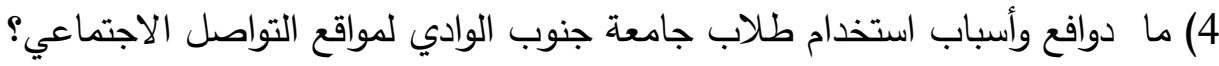
5) ما الموضوعات التي يفضل طلاب جامعة جنوب الوادي الاطلاع عليها عبر مواقع

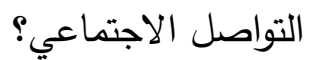
6) ما الجانب السلبي الذي تؤثر عليه مواقع التواصل الاجتماعي من وجهة نظر الطلاب

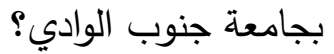
7) ما المخاطر الاجتماعية لمواقع التواصل الاجتماعي على طلاب جامعة جنوب الوادي؟ 8) ما المخاطر الأمنية لمواقع التواصل الاجتماعي على طلاب جاعت لامعة جنوب الوادي؟ 9) ما مقترحات الطلاب عينة الدراسة لتقليص الآثار السلبية لتلك لمواقع التواصل الاجتماعي؟

\section{حدود الاراسة:}

الحدود الموضوعية: اقتصرت الدراسة في مجالها الموضوعي على المخاطر الاجتماعية والأمنية لمواقع التواصل الاجتماعي على الطلاب بجامعة جنوب الوادي بقنا. الحدود المكانية: تغطي الدراسة طلاب جامعة جنوب الوادي بقنا في مختلف الكليات. الحدود الزمنية: تغطي الدراسة الطلاب المقيدين بكليات جامعة جنوب الوادي في الفصل

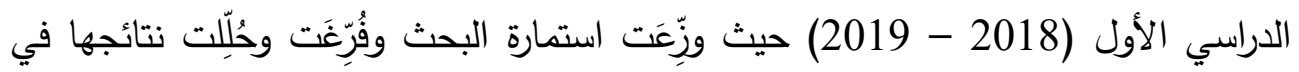


د. إيمان سيد عبد الحكيم

\section{مصطلحات الاراسة:}

التواصل: هو بناء علاقة بين فردين أو دولتين أو مجتمعين مما يحقق المنفعة المتبادلة بين الطرفين (إسماعيل، 2003).

الاجتماعي: مجموعة من الأفراد يربط بينهم رابط مشترك، يجعل هذه المجموعة تعيش عيشة

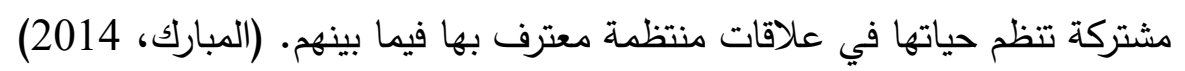
التواصل الاجتماعي: هو نقل الأفكار والتجارب وتبادل الأخبار والمعارف بين الذوات

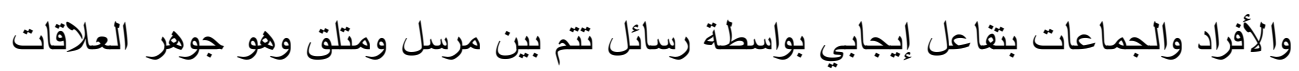

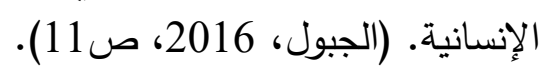

الشبكة الاجتماعية: عبارة عن شبكة مترابطة من الكيانات الفردية التي تتشارك في المصلحة المشتركة وتكتسب طريقة للتفاعل أو مشاركة المعلومات من خلال الخدمة. (Wuest , 2010 ,p1) مواقع التواصل الاجتماعي: منظومة من الشبكات الإكترونية تسمح للمشتركين بها إنشاء

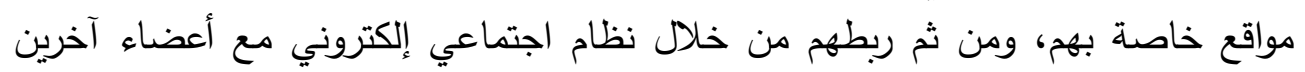

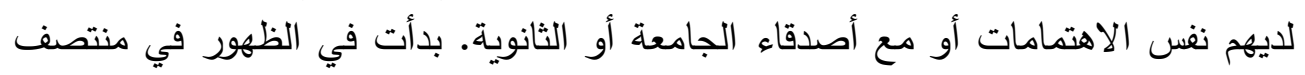
التسعينيات حيث أنشئ موقع (Classmates.com) عام 1995 للربط بين زملاء الدراسة، ثم موقع (SixDegrees.com) عام 1997 الذي ركز على الروابط المباشرة بين الأشخاص وأظهرت تلك المواقع الملفات الثخصية للمستخدمين وخدمة إرسال الرسائل

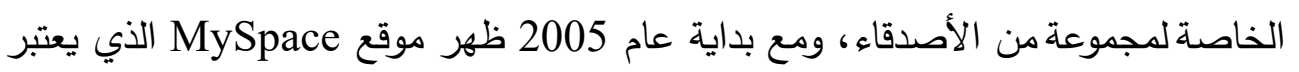

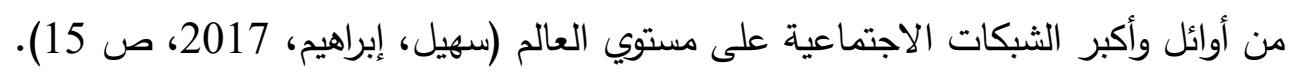
ومن أبرز مواقع التواصل الاجتماعي والأكثر انتشارا واستخداما في الوقت الحاضر ما يلي: الفيس بوك: يعد الموقع الاجتماعي الأكبر والأوسع على مستوى الثبكات العالمية

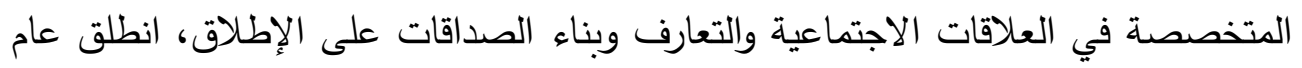

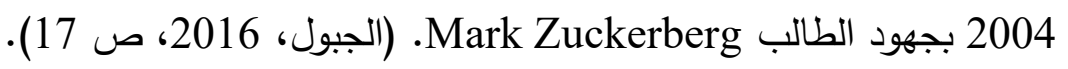
وقد وصل عدد المشتركين به بعد ست سنوات من عمره أكثر من 800 مليون

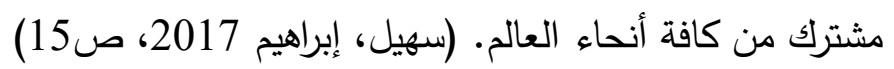
وترجع شهرة الفيس بوك إلى ثلاث مميزات جعلته الأكثر شعبية وهي القدرة على القى إضافة الأصدقاء وتحديث الحالة الشخصية وتشغيل تطبيقات مثل الألعاب، كما يسمح 
الفيس بوك لأي شخص مشترك به برؤية مستويات مختلفة من المعلومات الشخصية

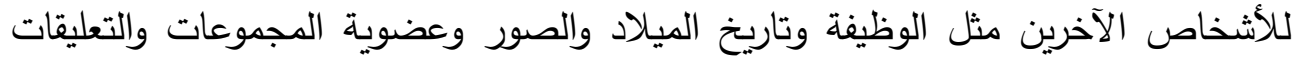
وقائمة الأصدقاء، كما يمكنه لعب الألعاب عبر الإنترنت وإبقاء الآخرين محدثين على وعلى الإنى حياتك اليومية.) (Dinerman , 2011 , p3)

تويتر: خدمة مدونة مصغرة في بداية عام 2010 عقدت أكثر من 75 مليون مستخدم مسجل يمكن لكل مستخدم نشر رسائل قصيرة تصل إلى 140 حرف في حسابه، ويمكن للمستخدمين الآخرين الاشتراك أو متابعة صفحة هذا الشخص وتلقي رسئي رسائل التحديث الخاصة بهم، وفي منتصف عام 2010 تعامل تويتر مع حوالي 750 رسالة في الثانية الواحدة

أو حوالي 65 مليون رسالة في اليوم الواحد مع معدل نمو حاد. (Wuest ,2010 , p2)

يوتيوب: الموقع الذي يسمح بتبادل ملفات الفيديو عبر تحميلها مجانا من غير أي قيود باستثناء الفيديوهات المخالفة للقوانين، ظهر عام 2005 وأتاح للمستخدمين رؤية فيديوهات غير احترافية مقدمه من الجمهور نفسه، ويعد نجاح اليوتيوب مبنيا على أن الجمهور أصبح يهتم بالفيديو القصير والمفيد من المادة الإعلامية المطولة وكذلك مجانيته وسهولة استخدامه. (الجبول، 2016، صنيوسير 19).

المخاطر الاجتماعية والأمنية: التأثيرات السلبية الملموسة الناتجة عن استخدام مواقع التواصل الاجتماعي مثل ما يتعلق بمشكلات التتكك الأسري والحث على العنف وإثارة البلبلة وغيرها من الآثار السلبية التي تؤثر ملى التئ الفرد والمجتمع.

طلاب الجامعة: فئة من الثباب تعدوا مرحلة الثانوية بحصولهم على البكالوريا ودخولهم إلى إلى

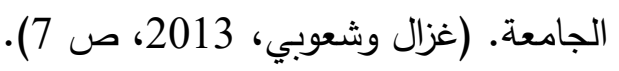

الاراسات السابقة:

هنالك العديد من الدراسات التي تطرقت لموضوع مخاطر مواقع التواصل الاجتماعي وتأثير استخدامه على الثباب بشكل خاص وعلى المجتمع بشكل عام، فمنها من تتاول أثرها

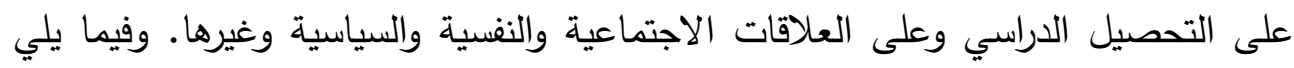
عرض موجز لبعض الدراسات التي تتاولت موضوع الدراسة: 
أولاً: الارلسات العربية:

أجرى (سهيل وإبراهيم، 2017) دراسة هدفت إلى معرفة تأثير استخدام مواقع الإبل

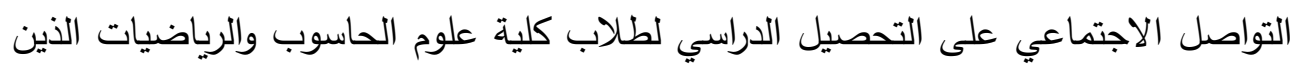

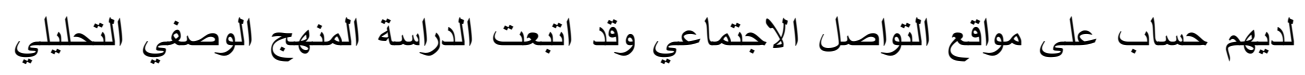

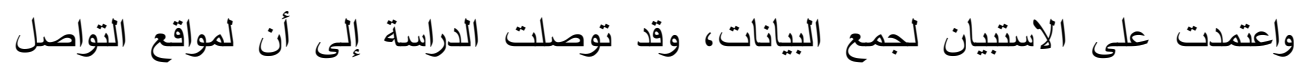

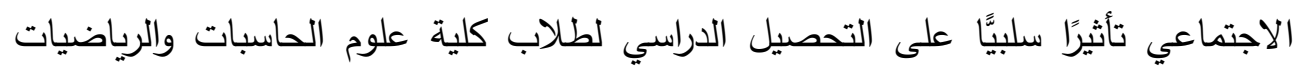

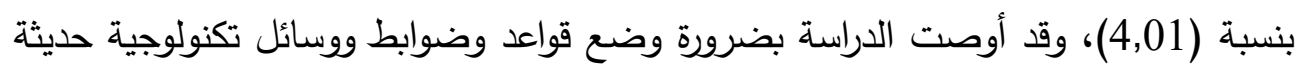

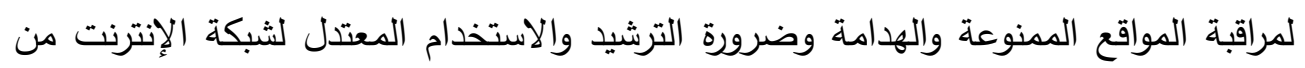
قبل الثباب.

كما أجرت (حنان، 2017) دراسة سعت للكثف عن تأثير شبكات التواصل

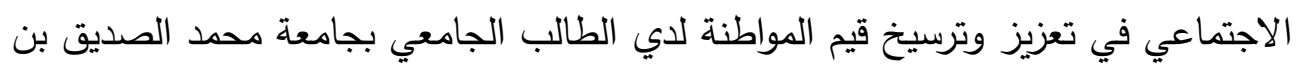

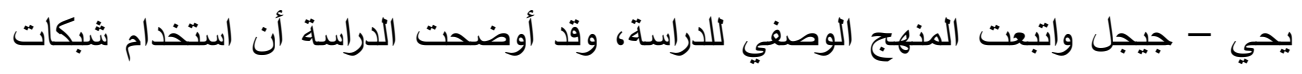

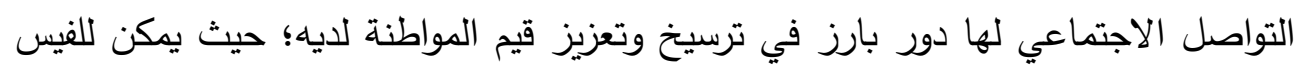

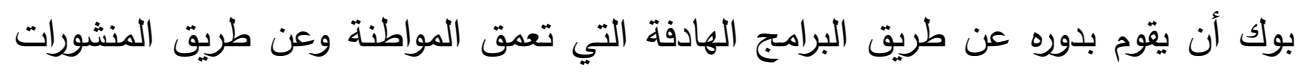

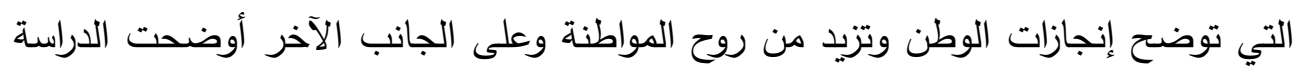

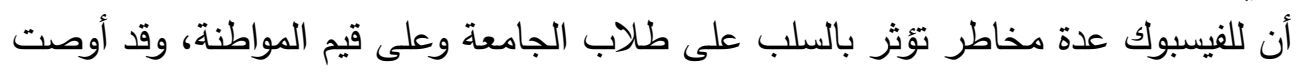

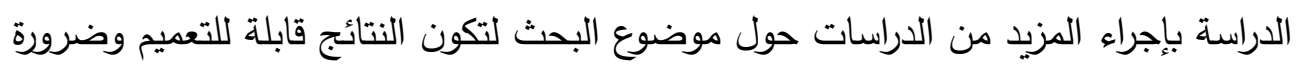

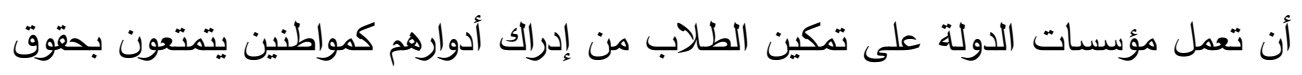

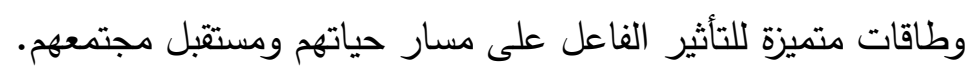

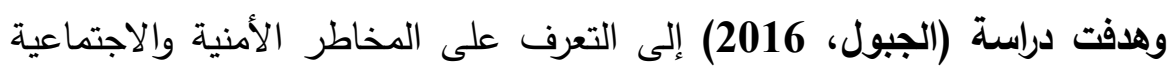

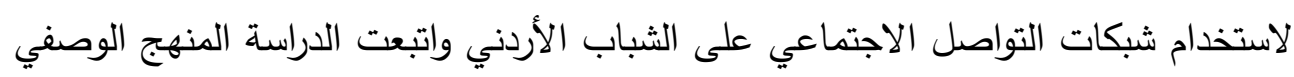

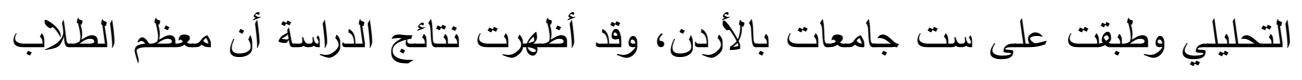

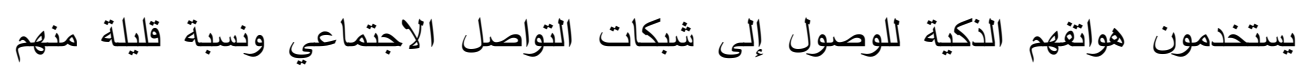

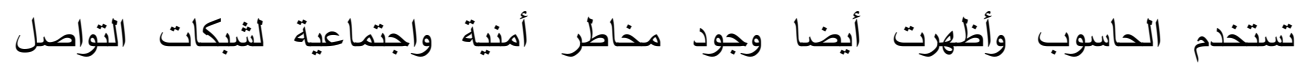

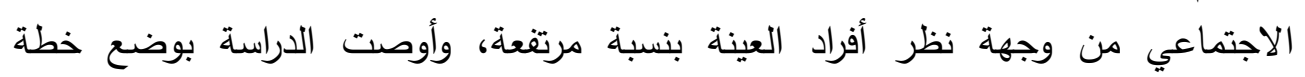

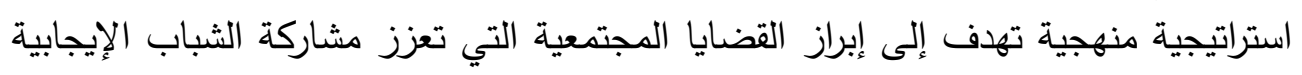

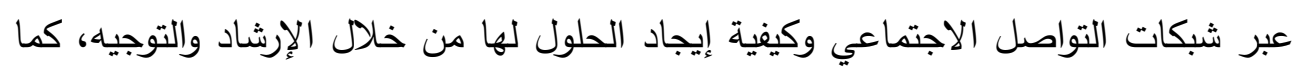

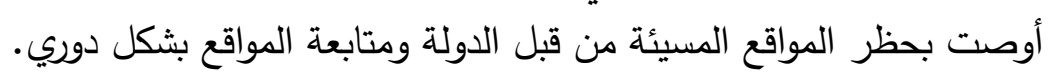


كما تناولت دراسة (اللبان، 2016) اتجاهات النخبة نحو تأثير مواقع التواصل الاجتماعي على الأمن القومي المصري ومعدل متابعة النخبة لتلك المواقع كمصدر للأخبار والمعلومات، واعتمدت الدراسة على المنهج المسحى، وقد توصلت الدراسة إلى ارتفاع معدل

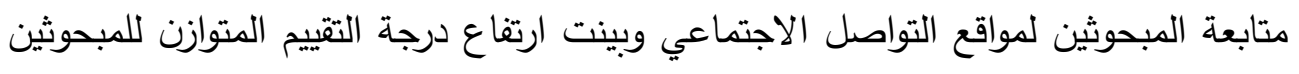

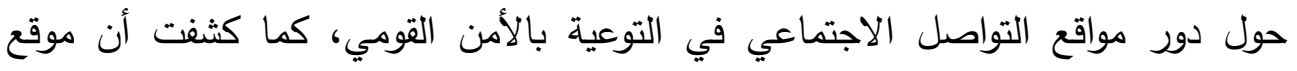

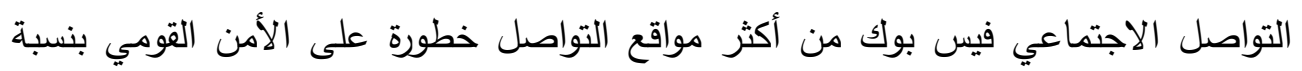

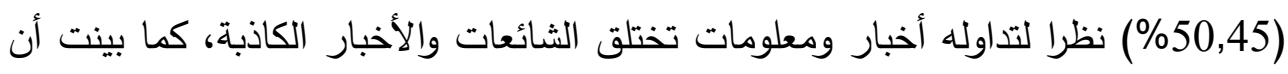

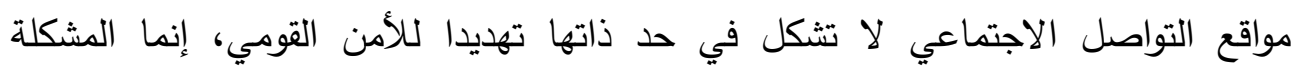
الحقيقية تتمثل في فكر مستخدميها والقائمين عليها، وقد أوصت الدارئ الداسة بتطوير الأجهزة الأمنية كي تستطيع فرض سيطرتها ورقابتها على مواقع التواصل الاجتماعي والعمل على فلى الإنى الإفادة من إيجابيات الشبكة.

كذلك تناولت دراسة (الماس، 2016) جهود المملكة العربية السعودية نحو مكافحة المواقع خاصة المواقع التي تظهر على شبكات التواصل الاجتماعي والتي تؤثر على القيم

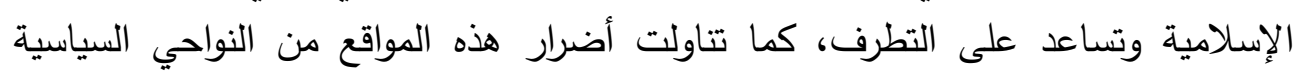

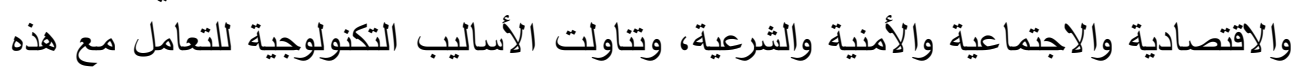

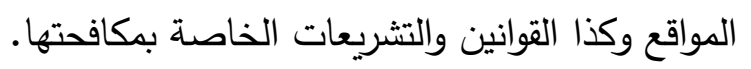

تعرضت دراسة (المتبولي، 2015) لدور شبكات التواصل الاجتماعي في التوعية السياسية والاجتماعية للشباب من طلاب جامعة طنطا وتأثير تلك الثبكات في حركات

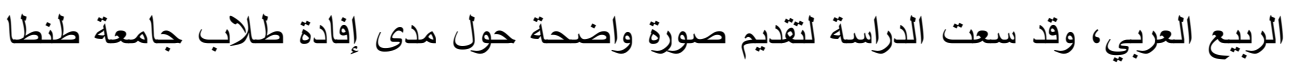

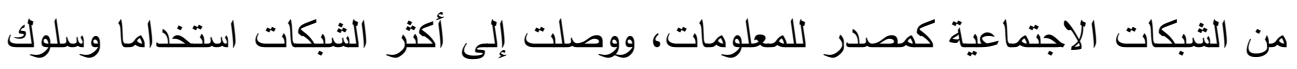
التعامل معها وتوجهات وآراء الطلاب نحو مديزاتها وعيوبها.

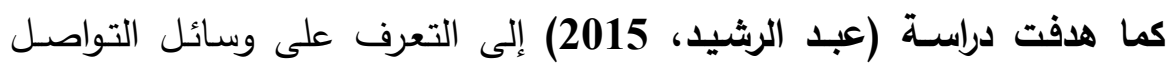
الاجتماعي وأثرها على الفرد والمجتمع وطرحت بعض الاقتراحات لتعزيز الجوانب الإيجابية

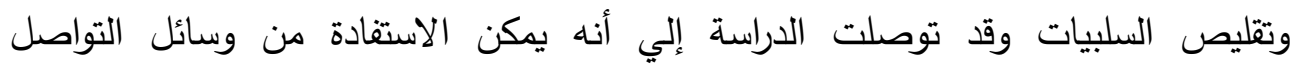

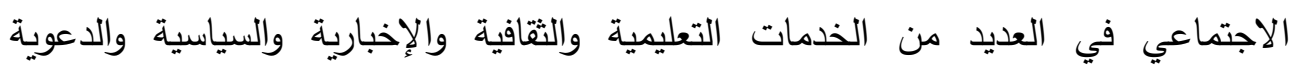

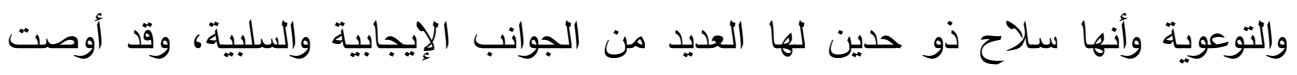

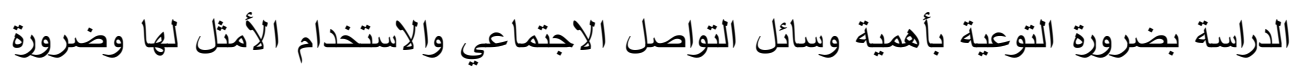


د. إيمان سيد عبد الحكيم

إجراء المزيد من الدراسات حول هذا الموضوع، وضرورة سن القوانين التي تجرم الاستخدام السيىء لها، وضرورة مراقبة الأبناء أثناء دخولهم على الإنترنت.

وأظهرت دراسة (شناوي وعباس، 2014) مستويات استخدام شبكة التواصل الاجتماعي

الفيس بوك وعلاقتها مع التوافق النفسي لدى الطلبة المراهقين واستخدمت الدراسة المنهج

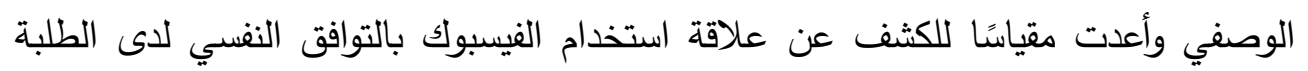

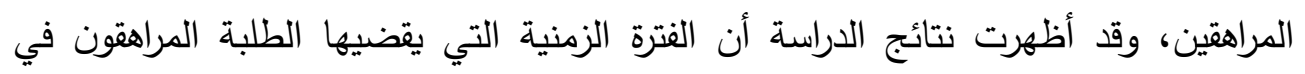
استخدام الفيسبوك هي أقل من ساعتين، وأن مستوى التوافق النفسي لدى الطلبة المراهقين

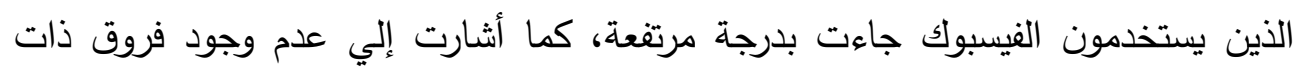

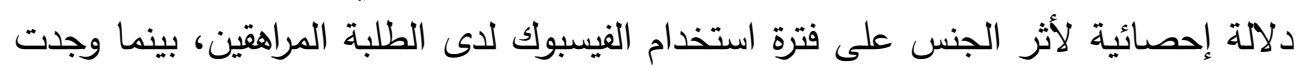

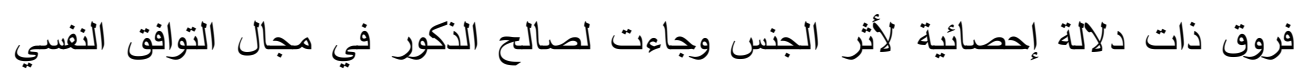

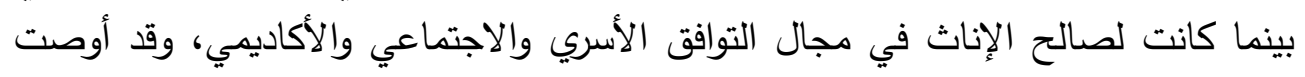

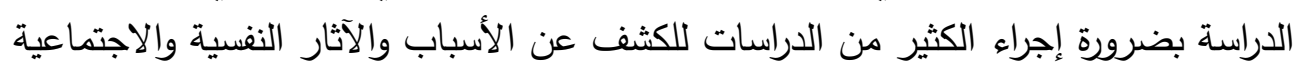

$$
\text { والتعليمية لاستخدام الفيس بوك على المراهقين. }
$$

وأجرى (غزال، 2014) دراسة هدفت إلى الكثف عن تأثير مواقع التواصل الاجتماعي

وتتمية الوعي السياسي من خلال دراسة عينة من الطلبة بجامعة قاصدي مرباح مستعملي

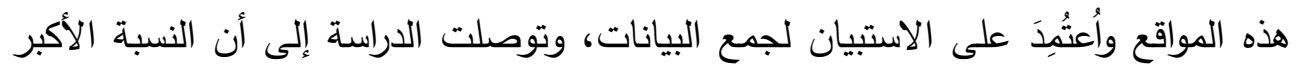

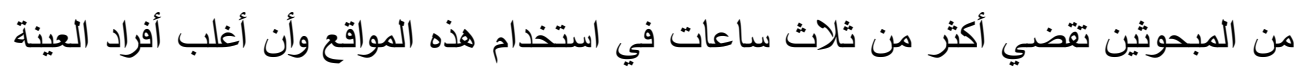

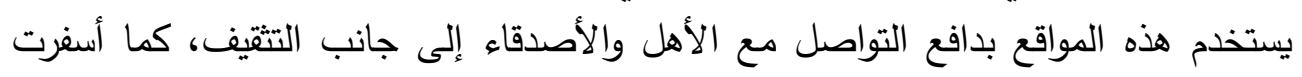

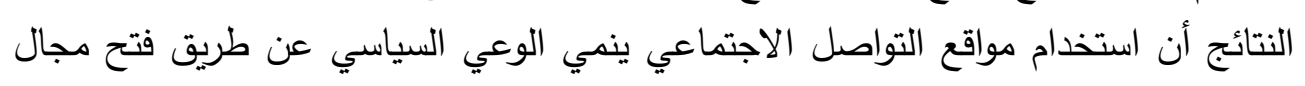

للمناقشة السياسية المفتوحة.

كذلك سعت دراسة (عوض، 2014) لمعرفة آثار استخدام مواقع التواصل الاجتماعي

على التحصيل الدراسي للأبناء في محافظة طول كرم من وجهة نظر ربات البيوت، وتكون

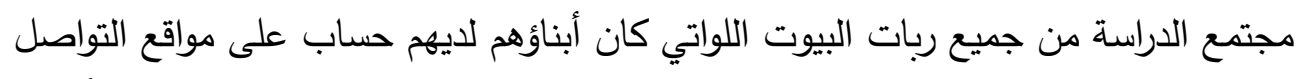
الدراسي واتبعت الدراسة المنهج الوصفي التحليلي، وتوصلت الدراسة إلى عدة نتائج أبرزها

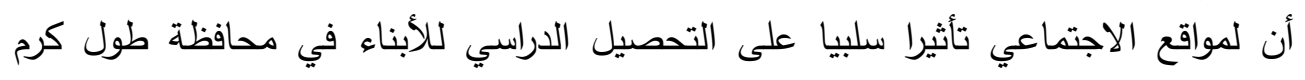

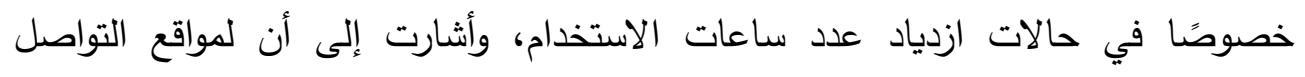

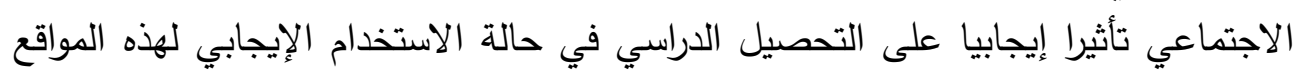

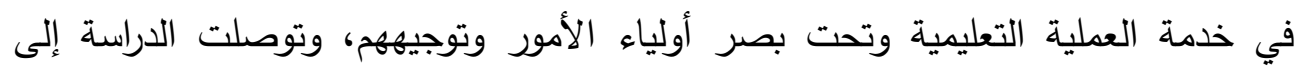


ضرورة استهداف الأمهات بحملات التوعية ووش العمر التي تهدف إلى رفع مستوي

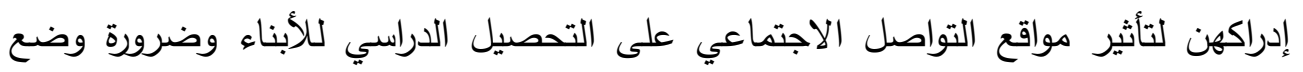

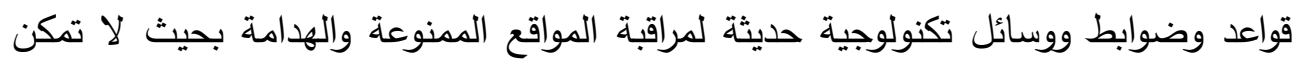
المستخدمين في الثبكة من الدخول إليها. وهدفت دراسة (بوسحلة و طهوري، 2014) إلى التعرف على الأسباب التي تدفع الطلبة إلى الاشتراك في موقعي الفيسبوك وتويتر والتعرف على طبيعة العلاقات الاجتماعية عبر هذه المواقع والكثف عن الآثار الإيجابية والسلبية الناتجة عن استخدامها، واعتمدت ولئي

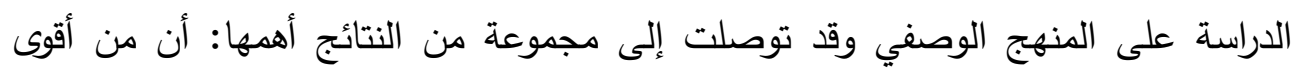
الأسباب التي تدفع الطلبة لاستخدام الفيسبوك وتويتر هي سهولة التعبير التيبر عن آرائهم واتجاهاتهم الفكرية التي لا يستطيعون التعبير عنها صراحة، وكذلك تعزيز صداقاتهم القديمة

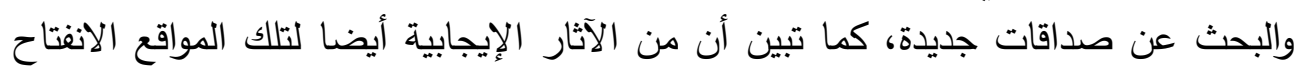

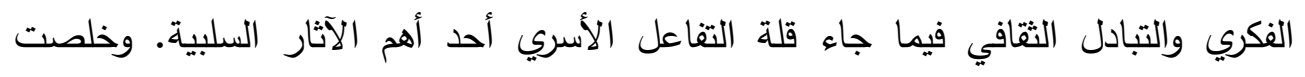

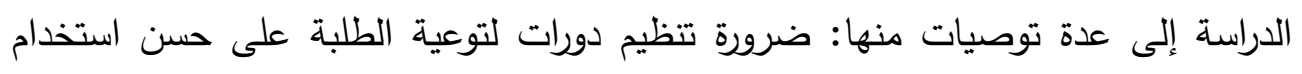
شبكات مواقع التواصل الاجتماعي والعمل على توظيف الإنترنت في عملية التعليم الأكاديمي.

وتعرف (الشهري، 2013) في دراسته على الأسباب التي تدفع للاشتراك في موقعي

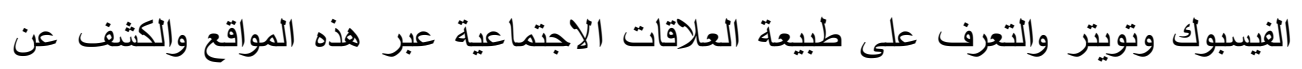

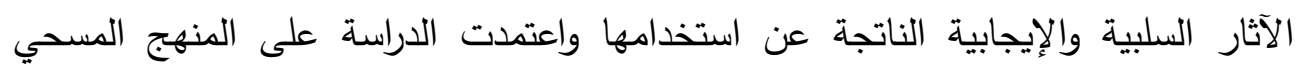

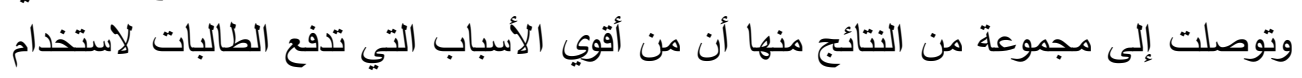
الفيسبوك وتويتر هي سهولة التعبير عن آرائهن واتجاهاتهن الفكرية التي لا يستطعن التهني التعبير

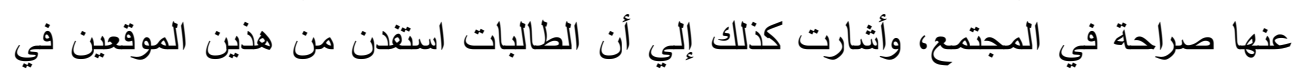
تعزيز صداقاتهن القديمة والبحث عن صداقات جديدة والتواصل مع أقاربهن البعيدين مكانيا، كما تبين أيضا أن لاستخدام الفيسبوك وتويتر العديد من الآثار الإيجابية أهمها الانفتاح

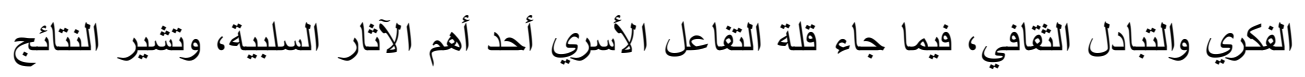

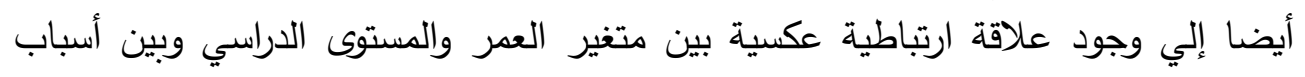

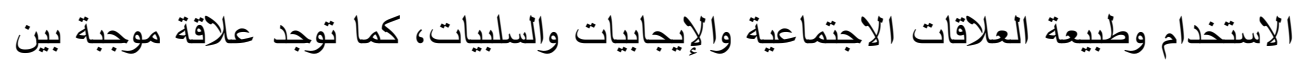

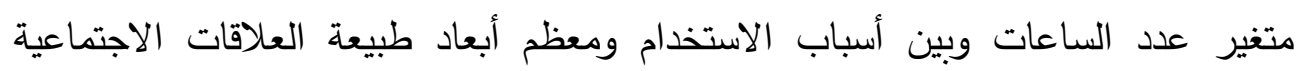
والإيجابيات، في حين أثبتت النتائج وجود علاقة ارتباط طردية بين متغير طريقة الاستخدام 
د. إيمان سيد عبد الحكيم

وبين أسبابه وطبيعة العلاقات الاجتماعية والإيجابيات والسلبيات، وخلصت الدراسة إلى دئ

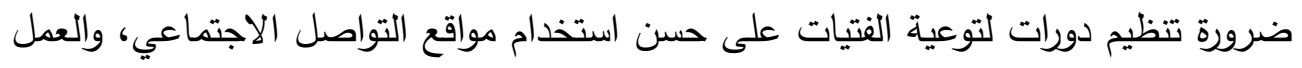
على توظيف تكنولوجيا الاتصالات الحديثة في عملية التعليم الأكاديمي. ومن ناحية أخري تناولت دراسة (أحمد وعمر، 2013): أثر وسائل التواصل

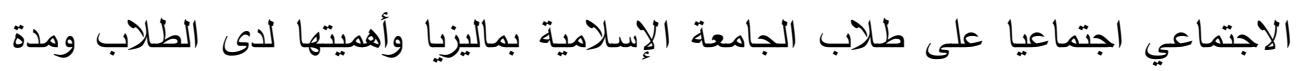

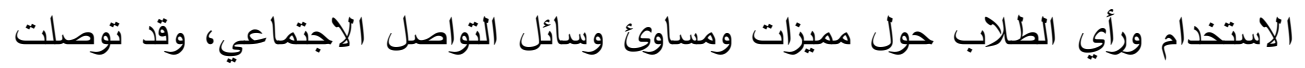
الدراسة إلى أن معظم الطلاب يستخدمون وسائل التواصل الاجتماعي للاتصال بالأصدقاء

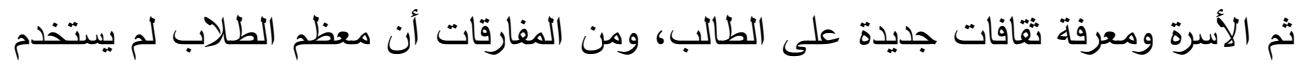

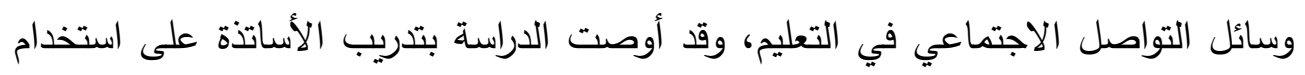
وسائل التواصل الاجتماعي في التعليم ومن ثم تدريب الطلاب ولتئ على الاستخدام الأمثل والوعي لوسائل التواصل الاجتماعي في التعليم.

وتقصت دراسة (الطراونة والفنيخ، 2012) عن أثر استخدام الإنترنت في التحصيل

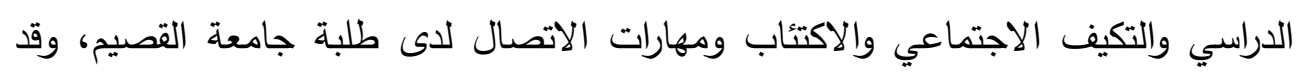

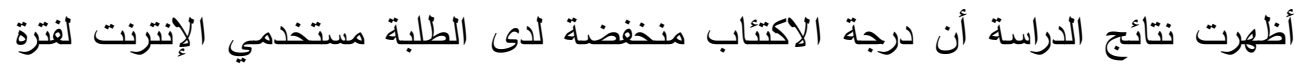

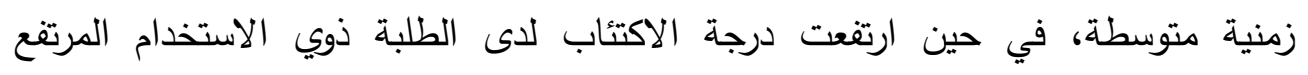

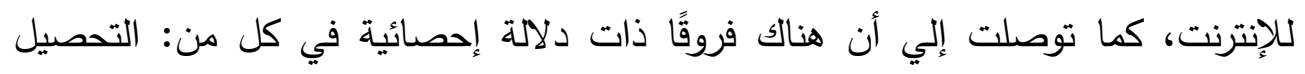
الدراسي، والتكيف الاجتماعي، تعزى لعدد ساعات استخدام الإنترنت والنوع الاجتماعي

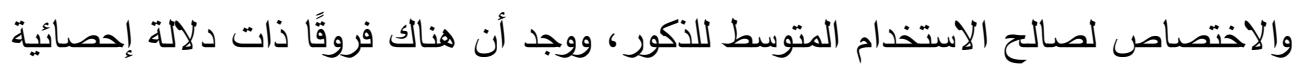
بين درجة الاكتئاب تعزى لعدد ساعات الاستخدام والنوع الاجتماعي والاختصاص لصاص لصالح الاستخدام المرتفع للإناث.

كما أجرى (عرقوب والخدام، 2012) دراسة وصفية تحليلية هدفت إلى معرفة تأثير

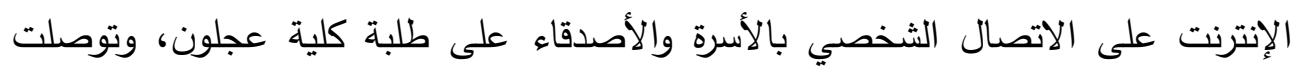

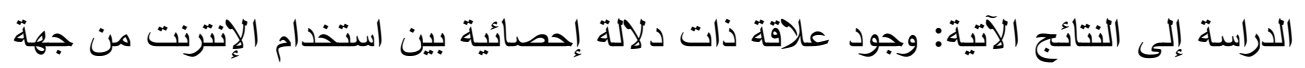

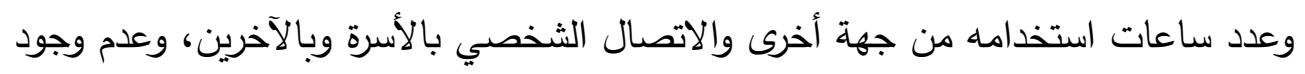
فروق ذات دلالة إحصائية لتأثير استخدام الإنترنت على الاتصال الثالهال الثخصي بالأسرة

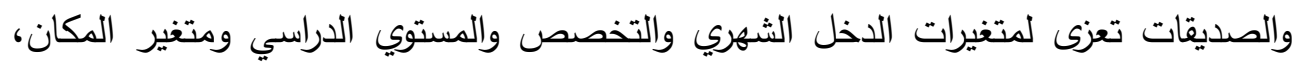

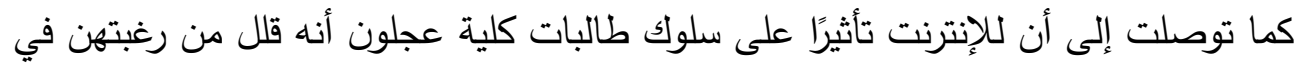

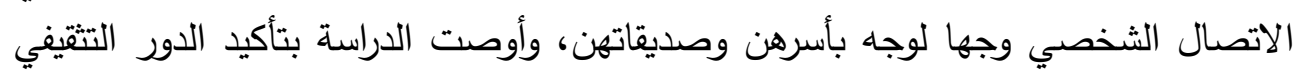


والتوعوي بإيجابيات الإنترنت وتأثيره على العلاقات الاجتماعية للشباب وأهمية تحذيرهم من مغبة استخدامه في القضايا السلبية. كذلك كشفت دراسة (نومار، 2012) عن أثر استخدام الشبكات الاجتماعية في

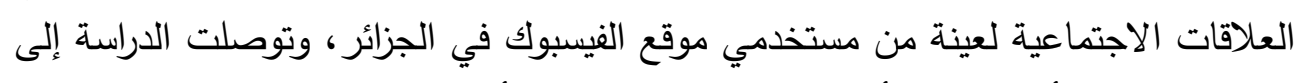
عدة نتائج منها: أن النسبة الأكبر من المبحوثين تقضي أكثر من ثلاث ساعينة ألاعات في استخدام الفيسبوك ويفضل أغلبهم خدمة التعليقات والدردشة بالدرجة الأولي، ويستخدم أغلب أفراد

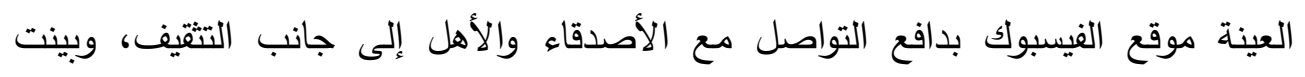

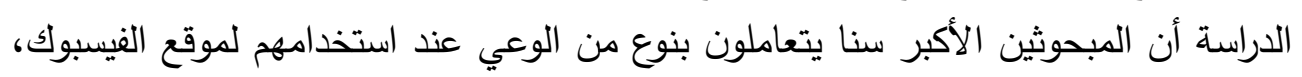

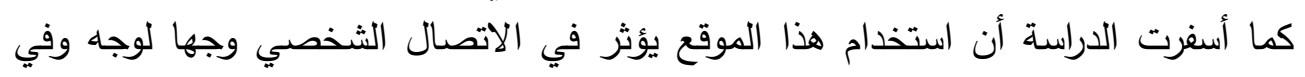

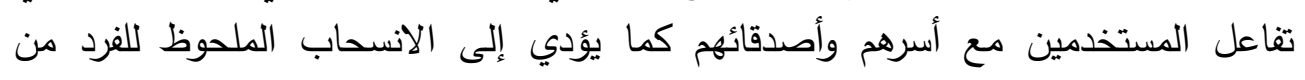

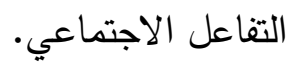

ثانيًا: الاراسات الأحنيـة:

تناولت دراسة (Eysenbach, 2017) استخدام الإنترنت وسلوك الوصول إليه والتسلط عبر الإنترنت، واتبعت الدراسة المنهج الوصفي واستخدمت الاستبيان لجمع البيانات

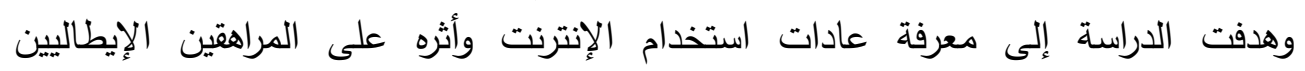

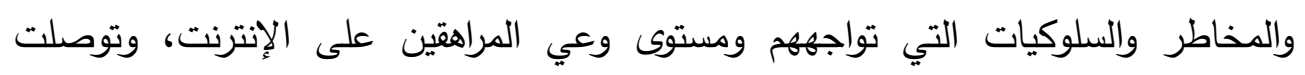

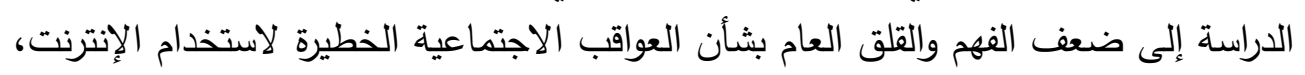

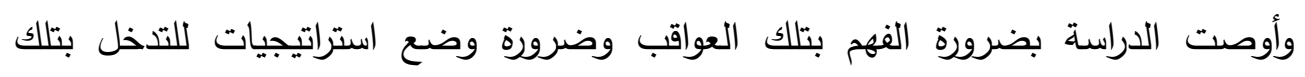

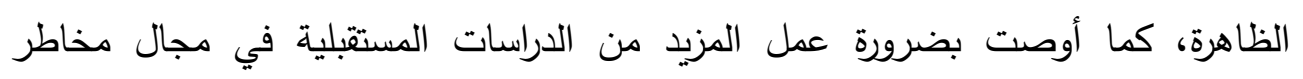

كما تناولت دراسة (Soebhektie, 2016) مخاطر استخدام خدمات الشبكات

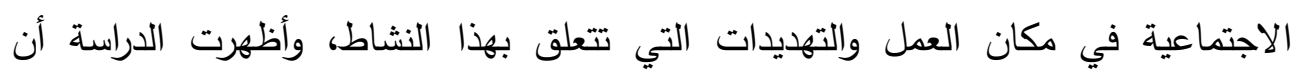
الشبكات الاجتماعية نافذة للإيذاء في مكان العمل وأن منصات فئن مواقع الثبكات الاجتماعية

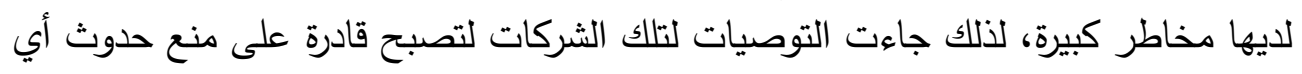
آثار ضارة قد تحدث نتيجة استخدام خدمات الشبكات الاجتماعية، وضرورة وضع سيات سياسة

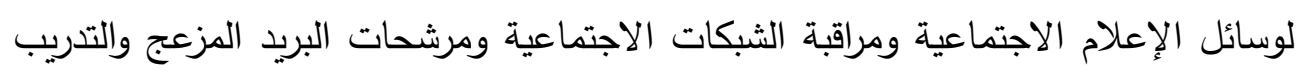
على أمن المعلومات وزيادة وعي الموظفين بمخاطر الثبكات الاجتماعية. 
كذلك سعت دراسـة (Kwonhoon\& koo, 2014) لتحديد العوامل النفسية

والاجتماعية لإدمان الإنترنت للكوريين والتعرف على الصعوبات في التعامل مع التحديات

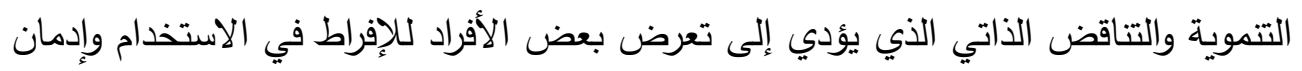

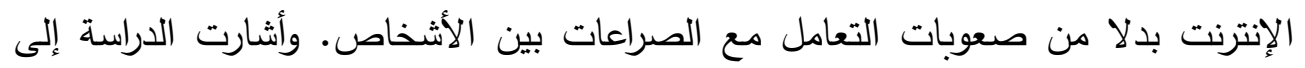

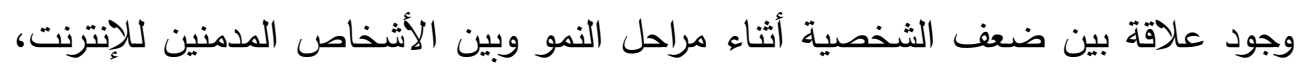

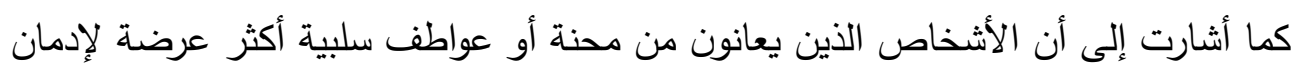

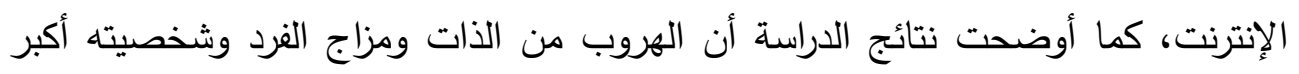

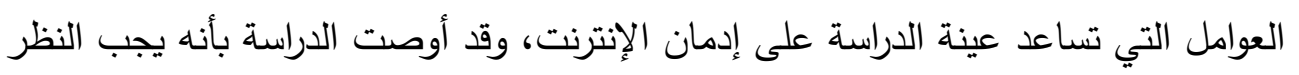

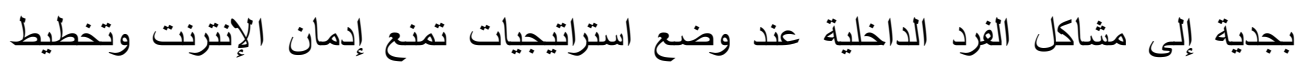

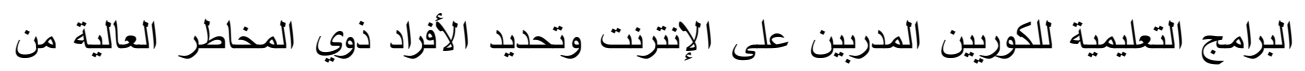
خلال الصفات النفسية بحيث يمكن تطوير طرق جديدة للحماية من إدمان الإنترنت. دراسة (Leung, 2014) التي تتاولت مخاطر الإنترنت وأعراض الإدمان واستخدام

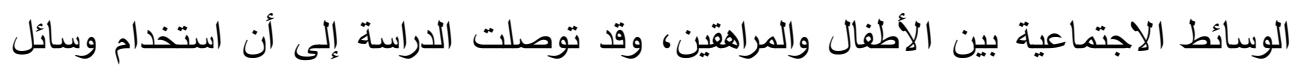

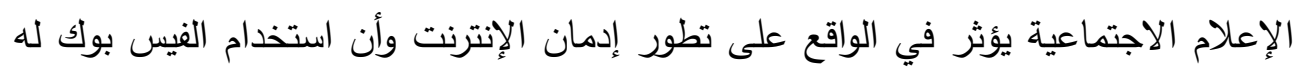

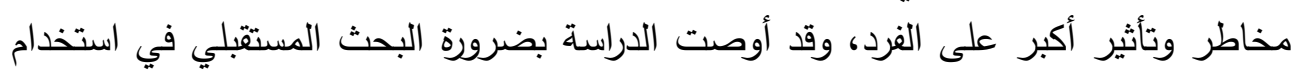

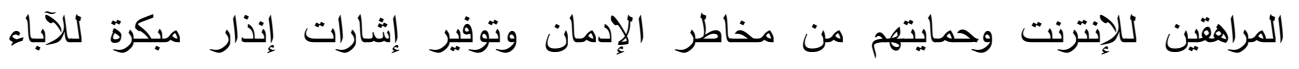
والمعلمين لتقليل احتمالية تعرض المراهقين لخطر الإدمان على الإنترنت من خلال النصان النصائح

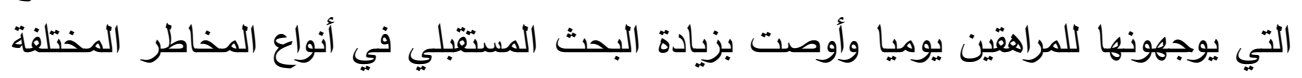
لإدمان الإنترنت.

أشارت أيضا دراسة (Dinerman, 2011) إلى أنه على الرغم من المميزات

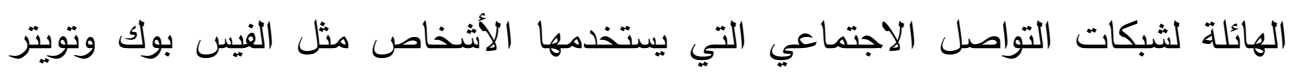

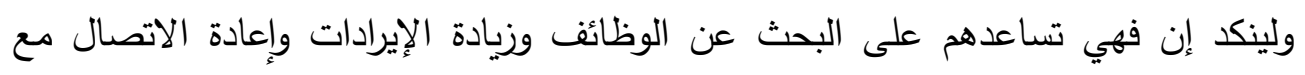

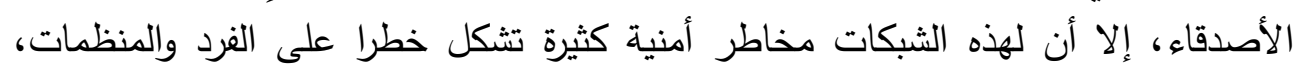

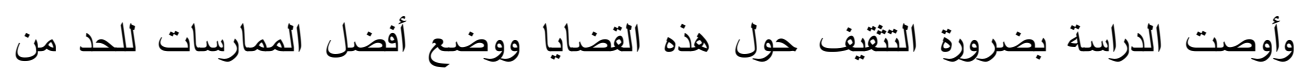
مخاطر الشبكات الاجتماعية.

كما جاءت دراسة (Goulet \& Kenth \& Hampton, 2011) للتعرف على

التأثير الاجتماعي لاستخدام الشبكات الاجتماعية مثل فيس بوك وتويتر وماي سبيس في

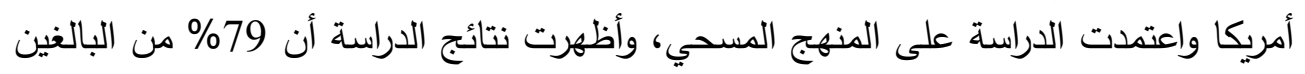


يستخدمون الإنترنت وأن متوسط عمرهم 38 سنة وأن 56\% من المستخدمين إناث وأن الفيس بوك هو أكثر المواقع استخداما حيث بلغت نسبة استخدامه وفي دراسة (Shen \& Khalifa, 2010) كثفت عن استخدامات الفيس بوك للى طلبة الجامعات في الإمارات العربية المتحدة مع التركيز على الفروق بين الجنسين في

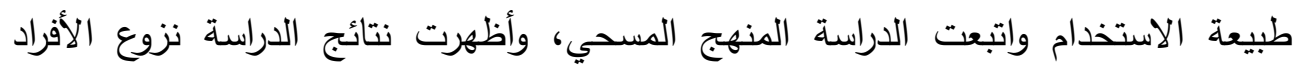
لاستخدام الفيس بوك غير المعروفين كواحد من الأسباب التي تمنعهم من توسيع شبكاتهم

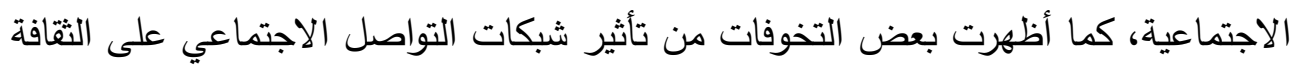

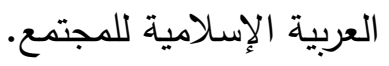

مدا تقدم يتبين أن معظم هذه الدراسات تناولت الموضوع من زوايا مختلفة؛ حيث تتاول البعض تأثير مواقع التواصل الاجتماعي على التحصيل الدراسي وعلى التوافق النفسي لأني

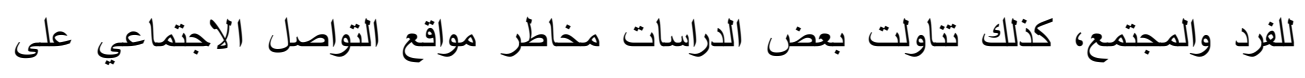

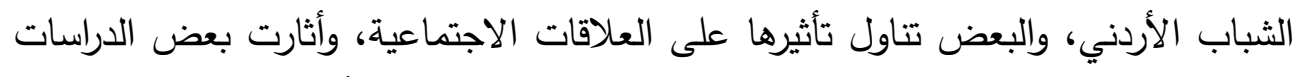

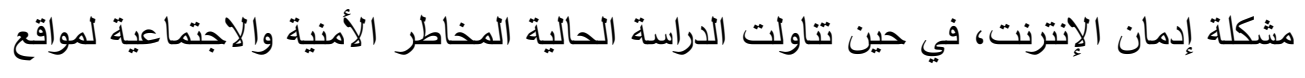

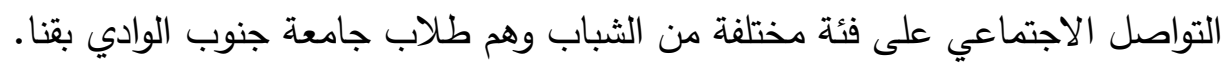

\section{منهج الدراسة:}

اعتمدت الدراسة على المنهج المسحي الذي يعد من أكثر المناهج الملائمة لدراسات

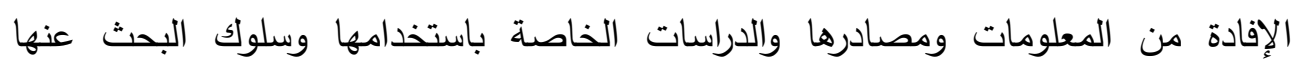
واتجاهات المستقيدين نحوها، حيث يقوم بوصف وتحليل وتفسير جوانب الموضوع المختلفة

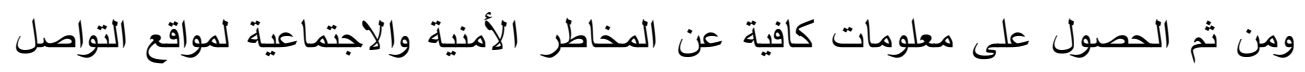
الاجتماعي لطلاب الجامعة بحيث يمكن تصنيفها وتحليلها وتفسيرها ثم تعميم نتائجها

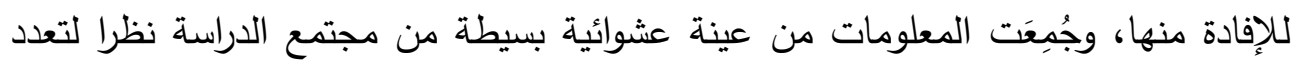

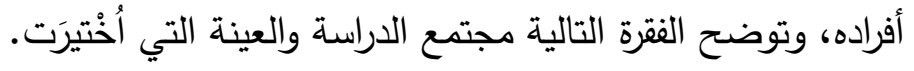

\section{مجتمع وعينة الدراسة:}


تكون مجتمع الدراسة من طلاب وطالبات جامعة جنوب الوادي بقنا المقيدين بالإدارة العامة لثؤون التعليم والطلاب الموزعين على مختلف الفروق لجميع الكليات للعام الجامعي (2018 - 2019) والبالغ عددهم (50013) طالبًا وطالبة. ونظرا لكبر حجم مجتمع الدراسة، أعْتُمِدَ على عينة عشوائية للإِفادة من أساليب

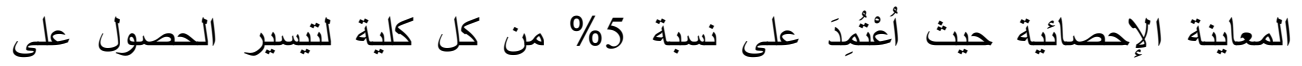
المعلومات، وبلغ إجمالي عدد الاستبانات التي وُزّزِعَت (2494) استبانة. والجدول التالي يوضح توزيع عينة الاراسة:

جدول رقم (1) توزيع عينة الدراسة وفقا لكل كلية

\begin{tabular}{|c|c|c|c|}
\hline النسبة المئويـة & العينة & العدد الكلي & الكلية \\
\hline$\% 5$ & 423 & 8467 & كلية الآداب \\
\hline$\% 5$ & 495 & 9900 & كلية التجارة \\
\hline$\% 5$ & 350 & 7007 & كلية الحقوق \\
\hline$\% 5$ & 445 & 8916 & كلية التربية \\
\hline$\% 5$ & 111 & 2235 & كلية التربية النوعية \\
\hline$\% 5$ & 141 & 2829 & كلية التربية الرياضية \\
\hline$\% 5$ & 66 & 1337 & كلية الهندسة \\
\hline$\% 5$ & 69 & 1384 & كلية الطب \\
\hline$\% 5$ & 28 & 567 & كلية الصيدلة \\
\hline$\% 5$ & 33 & 673 & كلية الطب البيطري \\
\hline$\% 5$ & 78 & 1561 & كلية الزراعة \\
\hline$\% 5$ & 31 & 627 & كلية العلاج الطبيعي \\
\hline$\% 5$ & 71 & 1427 & كلية العلوم \\
\hline$\% 5$ & 37 & 742 & كلية الآثار \\
\hline$\% 5$ & 41 & 824 & كلية التمريض \\
\hline$\% 5$ & 39 & 789 & كلية طب الأسنان \\
\hline$\% 5$ & 36 & 728 & كلية الإعلام \\
\hline$\% 5$ & 2494 & 50013 & المجموع \\
\hline
\end{tabular}


ومن خلا الجدول السابق، تبين أن إجمالي عينة الدراسة يبلغ (2494) طالبًا وطالبة من جميع الكليات محل الدراسة والتي تثكل نسبة 5\% من من إجمالي مجتمع الدراسة لتسهيل إجراء البحث وتطبيق الدراسة الميدانية.

أدوات جمع البيانات:

تطلبت الدراسة الاعتماد على الأداة الرئيسية لجمع البيانات الميدانية من عينة الدراسة

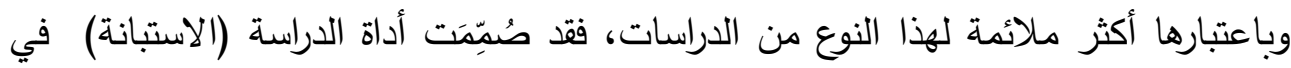

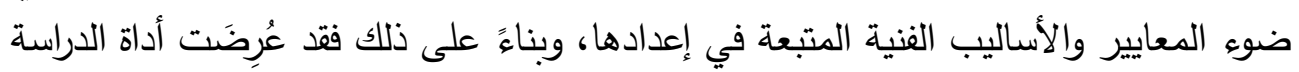

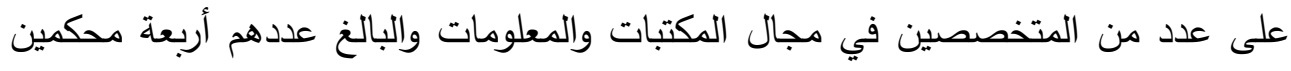
من الأساتذة المتخصصين (")، حيث طلب منهم إبداء رأيهم العلمي في المقياس عما إذا كان وان

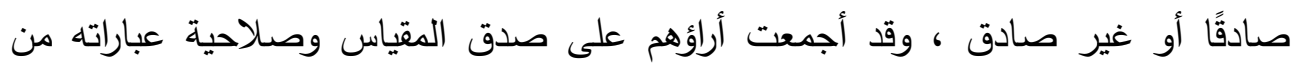
حيث الوضوح والملائمة وانعكاسها لأهداف الدراسة وقد أخذ في الحسبان آراء واقتراحات

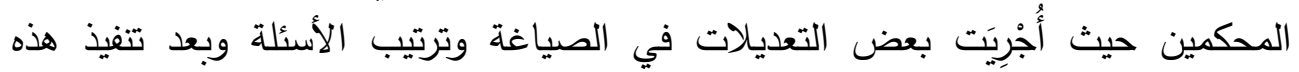

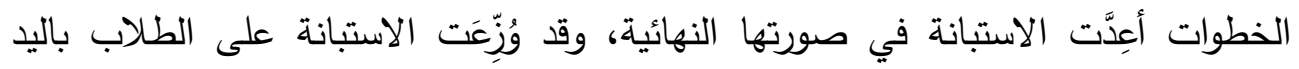

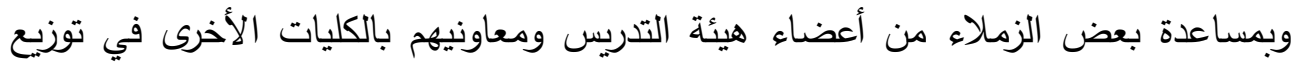

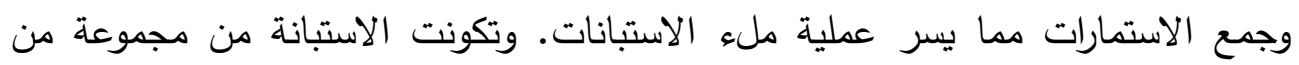

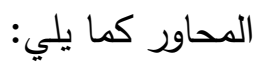
1- المحور الأول: البيانات الثخصية. 2- المحور الثاني: استخدام مواقع التواصل الاجتماعي.

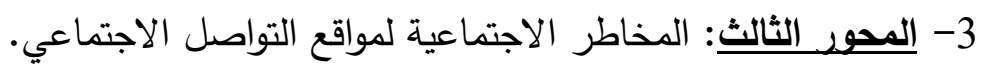

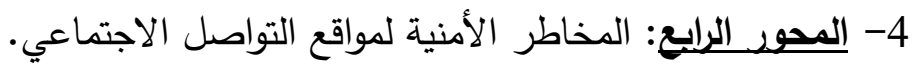

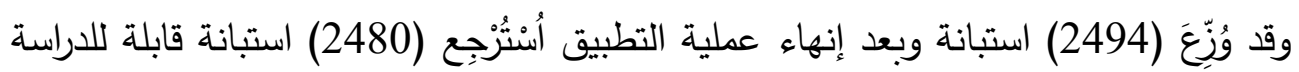
وبذلك بلغ عدد الاستمارات المستبعدة (14) استمارة بحث.

(أد/أساتذة محكمو الاستبانة.

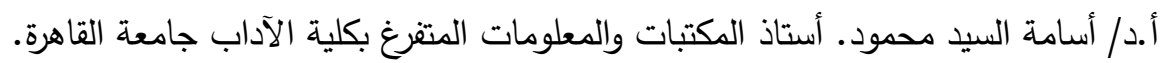

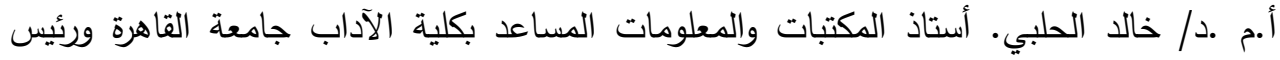

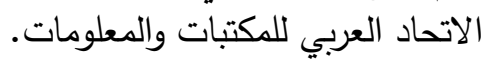

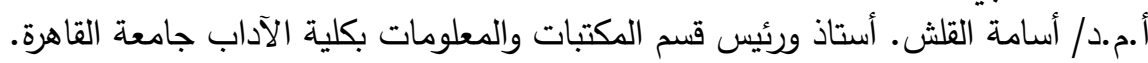

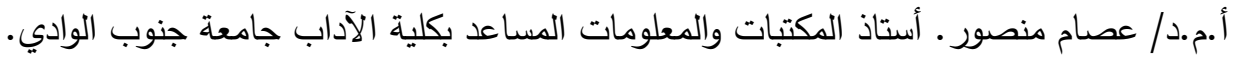


تحليل بيانات الاراسة ونتائجها:

المحور الأول: خصائص مجتمع الدراسة

(1) (الجنس: (1)

يوضح الجدول التالي التحليل الإحصائي لعينة الدراسة وفقا للجنس.

جدول رقم (2) توزيع العينة وفقا للجنس الإسي لئس

\begin{tabular}{|c|c|c|}
\hline النسبة المئوية & التكرار & الجنس \\
\hline$\% 20$ & 496 & ذ \\
\hline$\% 80$ & 1984 & أنثي \\
\hline$\% 100$ & 2480 & المجموع \\
\hline
\end{tabular}

من خلال الجدول السايق نستتبج الآتي:

- تفوق نسبة الإناث من أفراد عينة الدراسة على نسبة الذكور؛ حيث بلغت نسبة

الإناث (80\%) من إجمالي العينة في حين انخفضت نسبة الذكور، وربما يرجع الإناث

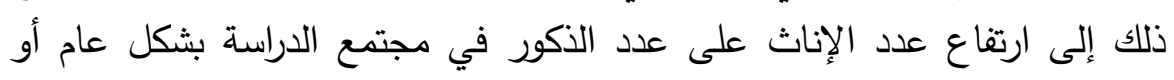

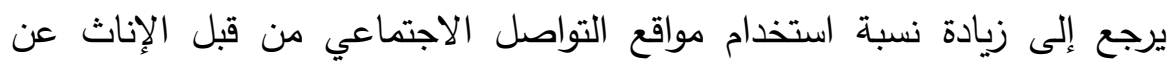

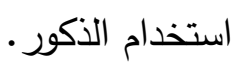

(2) محل الإقامةة:

يوضح الجدول التالي توزيع أفراد العينة وفقا لمحل الإقامة.

جدول رقم (3) توزيع العينة وفقا لمحل الإقامة

\begin{tabular}{|c|c|c|}
\hline النسبة المئوبـة & التكرار & محل الإقامة \\
\hline$\% 25$ & 620 & مدينة \\
\hline$\% 75$ & 1860 & قربية \\
\hline$\% 100$ & 2480 & المجموع \\
\hline
\end{tabular}


يتضــح مـن الجـدول السـابق ارتفـاع نسـبة المشـاركة في مـله اسـتمارة البحـث

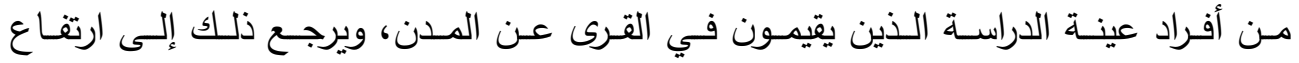

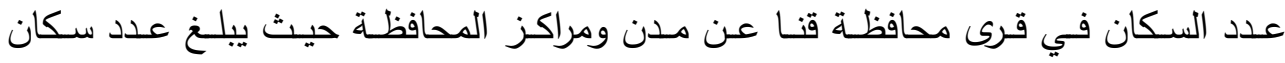

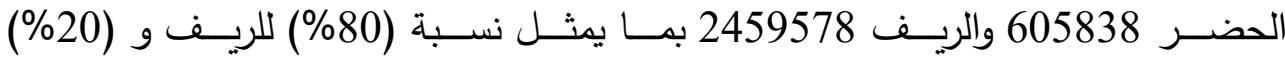
للحضـر (تقديرات مركـز المعلومـات ودعـم اتخـاذ القـرار بمحافظــة قــا)، وبالتـالي فـإنان عدد الطلاب من الريف يتفوق على عدد الطلاب من المدن.

(3) مستوي الاخل الثهري:

جدول رقم (4) توزيع أفراد العينة وفقا لمستوى الاخل الثهري

\begin{tabular}{|c|c|c|}
\hline النسبة المئوية & التكرار & الاخل الشهري \\
\hline$\% 33,5$ & 833 & أقل من 1000 \\
\hline$\% 42,7$ & 1053 & 1001 إلى 3000 \\
\hline$\% 13,1$ & 327 & 3001 إلى 5000 \\
\hline$\% 10,7$ & 267 & أكثر من 5000 \\
\hline$\% 100$ & 2480 & المجموع \\
\hline
\end{tabular}

وبدراسة واقع مستوى الدخل الثهري لأفراد العينة، تبين وجود تفاوت في الحالة الاقتصادية لأفراد عينة الدراسة، وهذا التفاوت قد يؤثر على نسبة اشتراكهم في مواقع الاجتماعي واستخدام الإنترنت، حيث نجد مؤشر الاخل الشهري يرتفع عند الفئة الثانية (من لهن

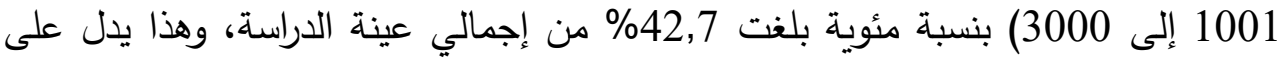
أن متوسط الدخل الشهري لعينة الدراسة ينحصر تحت هذه الفئة.

\section{المحور الثاني: استخدام مواقع التواصل الاجتماعي}

(1) امتلاك حساب شخصي على مواقع التواصل الاجتماعي

يوضح الثكل التالي مدى امتلاك أفراد عينة الدراسة لحساب شخصي على مواقع التواصل الاجتماعي من عدمه. 


\section{امتلاك حساب علي مواقع التواصل الاجتماعي}

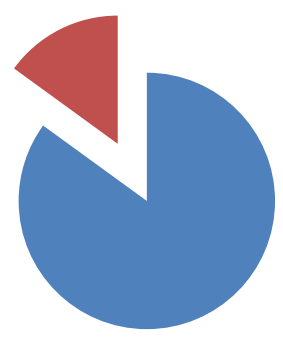

شكل رقم (1) امتلاك عينة الدراسة لحساب شخصي على مواقع التواصل الاجتماعي

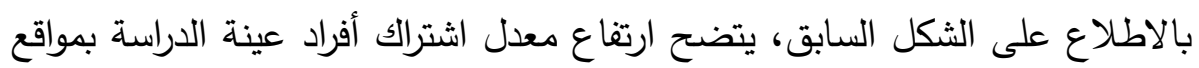

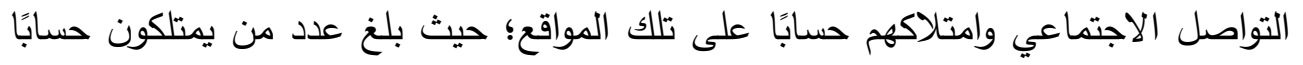
على مواقع التواصل الاجتماعي (2108) بنسبة 85\% من إجمالي عينة الدراسة، بينما

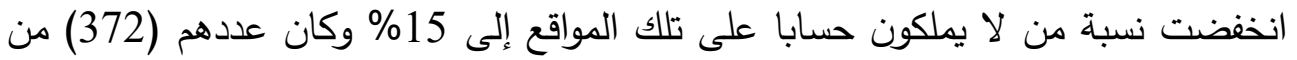

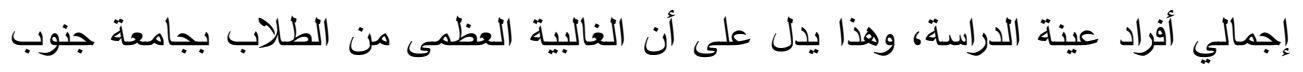

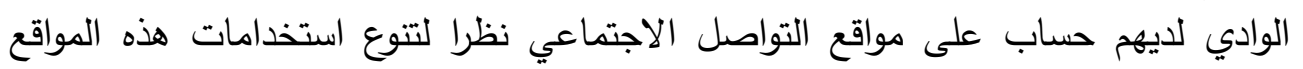

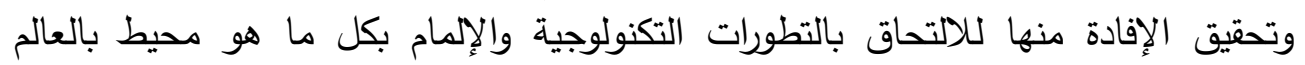

$$
\text { الخارجي عبر هذه المواقع. }
$$

(2) أسباب عدم استخدام مواقع التواصل الاجتماعي من قبل عينة الدراسة: جدول رقم (5) أسباب عدم استخدام مواقع التواصل الاجتماعي من قبل عينة الاعين الدراسة

\begin{tabular}{|c|c|c|}
\hline 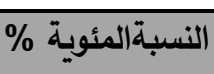 & الت التكرار & أسباب عدم استخدام مواقع التواصل الاجتماعي \\
\hline$\% 12$ & 45 & 1- عدم وجود الوقت الكافى \\
\hline$\% 35,4$ & 132 & 2- عدم توافر الإمكانيات المادية \\
\hline$\% 6,8$ & 26 & 3- عدم الرغبة في استخدام التكنولوجيا \\
\hline$\% 14,7$ & 55 & 4- يجعل الثخص انطوائيا ومنعزلًا عن الأسرة \\
\hline$\% 7,5$ & 28 & 5- مضيعة للوقت والجها وبسبب المشاكل \\
\hline$\% 8,6$ & 32 & 6- عدم توافر أجهزة ووسائل استخدام مواقع التواصل الاجتماعي \\
\hline$\% 15$ & 54 & 7- عدم موافقه الأهل على استخدام مواقع التواصل الاجتماعي \\
\hline$\% 100$ & 372 & المجموع \\
\hline
\end{tabular}


يتبين من نتائج الجدول رقم (5) أن عدم توافر الإمكانيات المادية لاستخدام مواقع التواصل الاجتماعي يأتي في المرتبة الأولي للأسباب التي صاغها أفراد عينة الدراسة عن لإن الإن عدم استخدام مواقع التواصل الاجتماعي بنسبة بلغت (35,4\%) من إجمالي العينة، وهذا ما يتوافق مع النتيجة التي توصلت إليها الدراسة في الجدول رقم (4) وهي أن متوسط الدخل الشهري لأفراد عينة الدراسة ينحصر في الفئة من (1001 إلى لـ 3000) ويعد هذا الدخل قليلًا إلي حد في ظل الظروف المعيشية التي تمر بها البلاد مما يقلل من اشترالك أفراد المجتمع في مواقع التواصل الاجتماعي الأمر الذي يتطلب توافر إمكانيات مادية تتاسب الاشتراك بتلك المواقع، لذا تفضل نسبة كبيرة من أفراد عينة الدراسة عدم الاشتراك بتلك المواقع توفيرا للنفقات.

يأتي في المرتبة الثانية عدم موافقة الأهل على استخدام مواقع التواصل الاجتماعي

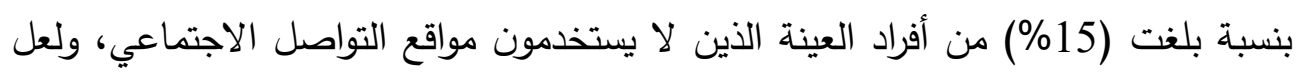

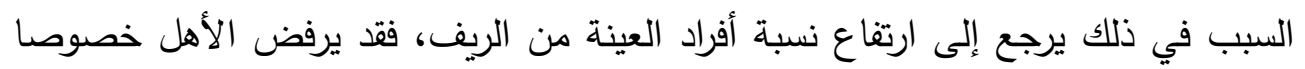
في الريف الاشتراك بتلك المواقع ظنا منهم أنها مواقع سيئة ترفضها العادات والتقاليد. في المرتبة الثالثة يشير أفراد العينة إلى أن مواقع التواصل الاجتماعي تجعل الشخص انطوائيا ومنعزلا عن المجتمع بنسبة بلغت (14,7\%) مما يجعلهم ينصرفون عن

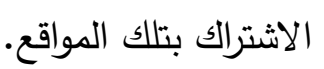
كذلك أثار أفراد عينة الدراسة إلي عدم وجود الوقت الكافي لاستخدام مواقع التواصل الاجتماعي حيث بلغت نسبتهم (12\%) من إجمالي العينة، وربما يرجع ذلك إلى أن أفراد العينة من طلاب منشغلون بدراستهم ولا يوجد لديهم الوقت الكافي للولوج إلى مواقع التواصل الاجتماعي في تلك المرحلة من عمرهم. بالإضافة إلى تلك الأسباب، سرد أفراد عينة الدراسة أسبابًا أخرى لعدم اشتراكهم بمواقع التواصل الاجتماعي وكان منها عدم توافر أجهزة ووسائل استخدام مواقع التواصل الاجتماعي وأن مواقع التواصل الاجتماعي مضيعة للوقت والجهد ويسبب المشاكل وكذلك عدم الرغبة عند البعض في استخدام التكنولوجيا ومواقع التواصل الاجتماعي بشكل عام. 
د. إيمان سيد عبد الحكيم

(3) طيعة الأحهزة المستخدمة كوسيلة للاتصال على مواقع التواصل الاجتماعي:

يوضح الجدول التالي التوزيع النسبي لنوع الأجهزة المستخدمة من قبل عينة الدراسة

$$
\text { للاتصال على مواقع التواصل الاجتماعي. }
$$

جدول رقم (6) نوع الأجهزة المستخدمة للاتصال بمواقع التواصل الاجتماعي

\begin{tabular}{|c|c|c|}
\hline | النسبة المئوية \% & التكرار (5) & الجهاز \\
\hline$\% 8,5$ & 180 & 1- حاسب شخصي \\
\hline$\% 14$ & 295 & 2- حاسب محمول (لاب توب) \\
\hline$\% 16,7$ & 353 & 3- حاسب لوحي (أيباد - تابلت) \\
\hline$\% 60,8$ & 1280 & 4- هاتف محمول \\
\hline$\% 100$ & 2108 & المجموع \\
\hline
\end{tabular}

يتضح من الجدول رقم (6) أن (60,8\%) من الطلاب عينة الدراسة يفضلون

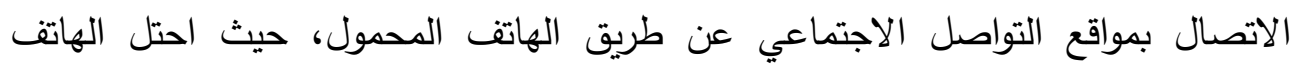
المحمول المرتبة الأولى من الأجهزة المستخدمة كوسيلة للاتصال بمواقع التواصل فلتصل الاجتماعي، وجاء الحاسب اللوحي في المرتبة الثانية بنسبة بلغت (16,7\%) ثم الحاسب الاسب المحمول في المرتبة الثالثة بنسبة بلغت (14\%) وأخيرا الحاسب الثخصي بنسبة بلغت (88,5) من الطلاب عينة الدراسة. ولعل أسباب ذلك ترجع إلى سهولة حمل الهاتف المحمول والتنقل به وإمكانية

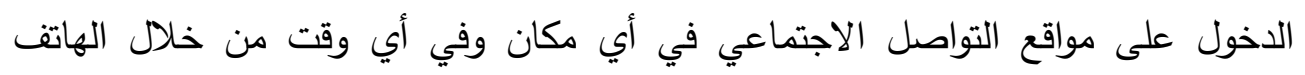
المحمول.

(4) مواقع التواصل الاجتماعي الأكثر زيارة من قيل الطلاب عينة الدراسة: يبين الجدول والشكل التالي ترتيب مواقع التواصل الاجتماعي الأكثر استخداما من قبل

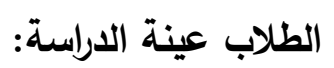


المخاطر الاجتماعية والأمنية لمواقع التو اصل الاجتماعي على عينة من الطلاب بجامعة جنوب الو ادي بقنا

جدول رقم (7) مواقع التواصل الاجتماعي الأكثر استخداما من قبل الطلاب عينة الدراسة

\begin{tabular}{|c|c|c|}
\hline النسبة المئوية \% & التكرار (ك) & مواقع التواصل الاجتماعي \\
\hline$\% 68,8$ & 1450 & 1- الفيس بوك \\
\hline$\% 5,2$ & 110 & 2- 2 تويتر \\
\hline$\% 22,8$ & 480 & 3- يوتيوب \\
\hline$\% 3,2$ & 68 & 4- مواقع التواصل الأخرى \\
\hline$\% 100$ & 2108 & المجموع \\
\hline
\end{tabular}

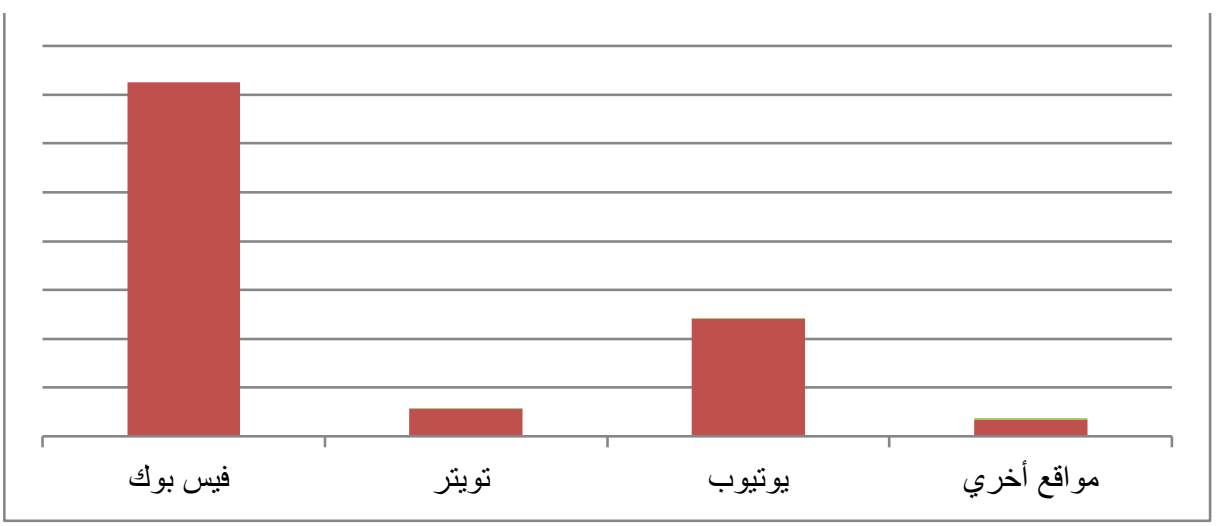

شكل رقم (2) مواقع التواصل الاجتماعي الأكثر استخداما من قبل عينة الدراسة وبقراءة نتائج الجدول رقم (7) والثكل رقم (2) يتبين الآتي:

- احتل موقع التواصل الاجتماعي الفيس بوك المرتبة الأول في المواقع الأكثر استخداما من قبل الطلاب عينة الدراسة بنسبة بلغت (68,8\%)، يليه في المرتبة الثانية اليوتيوب بنسبة بلغت (22,8\%)، ثم تويتر في المرتبة الثالثة بنسبة

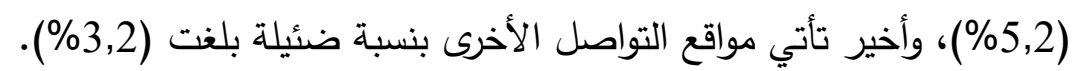

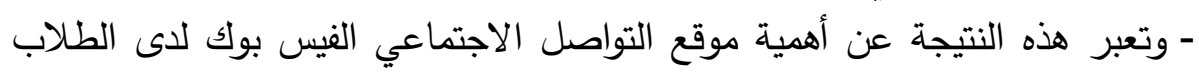

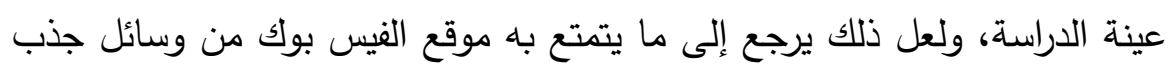

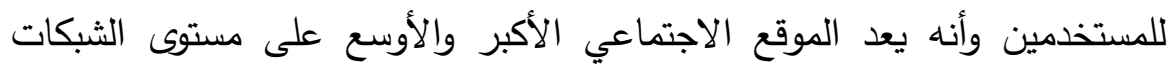

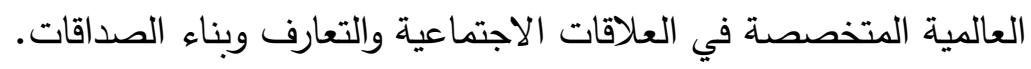


د. إيمان سيد عبد الحكيم

(5) عدد ساعات الاستخدام اليومية لمواقع التواصل الاجتماعي من قيل عينة الدراسة: جدول رقم (8) عدد ساعات الاستخدام اليومية لمواقع التواصل الاجتماعي

\begin{tabular}{|c|c|c|}
\hline النسبة المئوبـة \% & التكرار (5) & عدد ساعات الاستخدام يوميا \\
\hline$\% 25$ & 527 & ساعة أو أقل يوميا \\
\hline$\% 24,7$ & 520 & أقل من ساعتين يوميا \\
\hline$\% 25,7$ & 543 & من 2 إلي 5 ساعات يوميا \\
\hline$\% 24,6$ & 518 & أكثر من 5 ساعات يوميا \\
\hline$\% 100$ & 2108 & المجموع \\
\hline
\end{tabular}

يبين الجدول رقم (8) ساعات استخدام الطلاب محل الدراسة لمواقع التواصل الاجتماعي يوميا ويلاحظ تقارب النسب بين ساعات الاستخدام وأن الفروق بين نسب ساعات الاستخدام اليومية ضئيلة جدا، وتشير نتائج الجدول السابق إلي أن غالبية الطلاب محل الدراسة

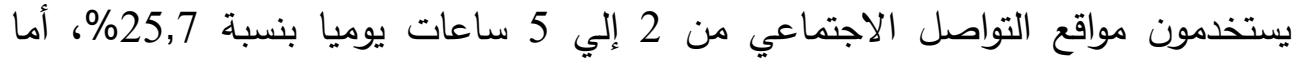

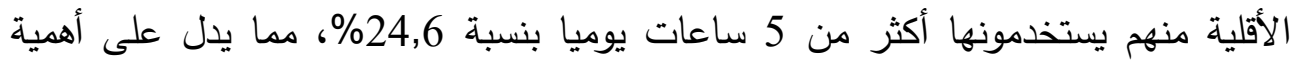
مواقع التواصل الاجتماعي للطلاب من أفراد عينة الدراسة.

(6) مدى تكرار الاخول على مواقع التواصل الاجتماعي من قبل عينة الاراسة: مدى تكرار الاخول لمواقع التواصل الإجتماعي

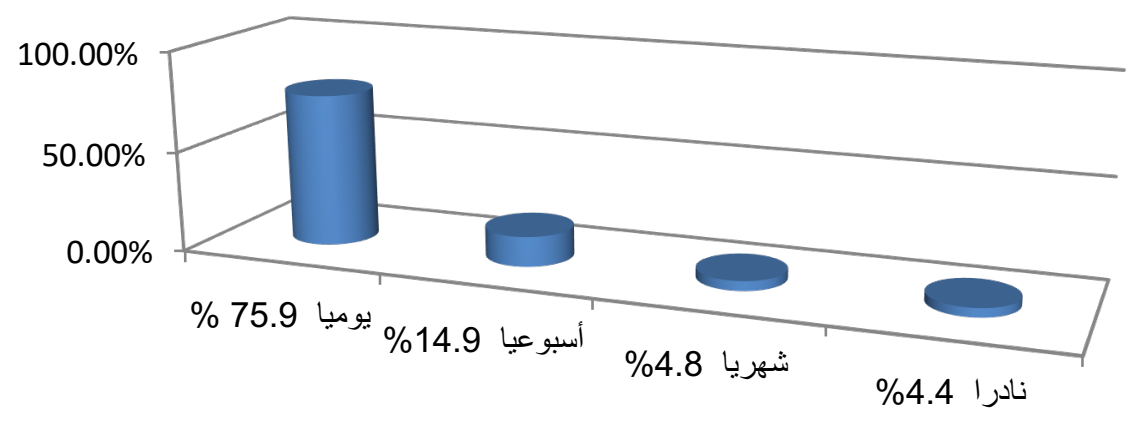

شكل رقم (3) مدى تكرار الاخول لمواقع التواصل الاجتماعي من قبل عينة الدراسة 
بدراسة واقع تكرار دخول الطلاب عينة الدراسة على مواقع التواصل الاجتماعي،

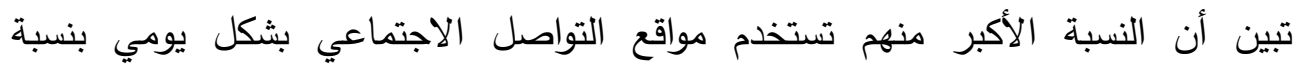

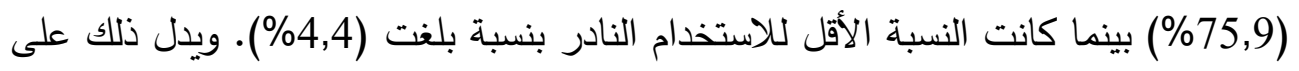
أهمية مواقع التواصل الاجتماعي للطلاب عينة الدراسة.

\section{(7) دوافع وأسباب استخدام مواقع التواصل الاجتماعي من قيل عينة الدراسة:}

يوضح الجدول التالي الأسباب التي تدفع الطلاب أفراد عينة الدراسة لاستخدام

$$
\text { مواقع التواصل الاجتماعي والإقبال عليها. }
$$

\section{جدول رقم (9) دوافع استخذام مواقع التواصل الاجتماعي من قبل عينة الدراسة}

\begin{tabular}{|c|c|c|c|c|c|c|c|c|c|c|c|}
\hline \multirow{2}{*}{ المنوال } & \multicolumn{2}{|c|}{ غير قوي جدا } & \multicolumn{2}{|c|}{ غير قوي } & \multicolumn{2}{|c|}{ محايد } & \multicolumn{2}{|c|}{ قوي } & \multicolumn{2}{|c|}{ قوي جدا } & \multirow{2}{*}{ أسباب ودوافع الاستخدام } \\
\hline & $\%$ & العدد & $\%$ & العدد & $\%$ & العدد & $\%$ & العدد & $\%$ & العدد & \\
\hline قوي & $\% 0,9$ & 19 & $\% 6,8$ & 145 & $\% 24,6$ & 520 & $\% 39,5$ & 843 & $\% 28.2$ & 599 & 1-التسلية والترفيه \\
\hline قوي جدا & $\% 0,9$ & 19 & $\% 4,8$ & 102 & $\% 16$ & 356 & $\% 28,1$ & 599 & $\% 50,2$ & 1060 & 2- التثقيف واكتساب \\
\hline ق قوي جدا & $\% 5,4$ & 115 & $\% 5,8$ & 123 & $\% 13,1$ & 277 & $\% 27,5$ & 580 & $\% 48,2$ & 1017 & 3- التواصل مع الآخرين \\
\hline محايد & $\% 12$ & 270 & $\% 14$ & 298 & \%38,3 & 810 & $\% 18,2$ & 380 & $\% 17,5$ & 370 & 4-تكوين صداقات جديدة \\
\hline قوي جدا & $\% 1$ & 23 & $\% 0,9$ & 19 & $\% 4,3$ & 91 & $\% 33,6$ & 710 & $\% 60,2$ & 1270 & الجارية ومتابعة الأخبار الأحداث \\
\hline قوي جدا & $\% 27$ & 580 & $\% 21,4$ & 452 & $\% 20,6$ & 435 & $\% 11,8$ & 250 & $\% 19,2$ & 405 & 6-الهروب من الواقع \\
\hline ق قوي جدا & $\% 4,8$ & 102 & $\% 8,3$ & 175 & $\% 13$ & 277 & $\% 33,6$ & 710 & $\% 41,2$ & 870 & 7-قضاء وقت الفراغ \\
\hline قوي جدا & $\% 4,7$ & 99 & $\% 13,1$ & 277 & $\% 20,6$ & 435 & $\% 24,6$ & 520 & $\% 37$ & 780 & 8-التخلص من القلق \\
\hline
\end{tabular}

وبراسة نتائج الجدول رقم (9) يمكن الخروج بالمؤشرات الآتية:

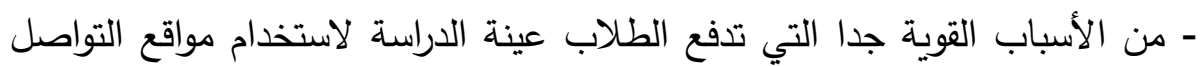

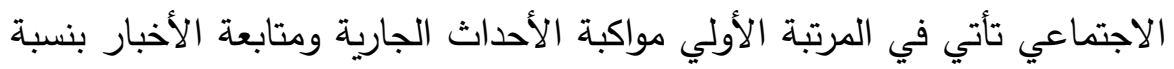
بلغت 60,2\%، مما يشير إلي أهمية مواقع التواصل الاجتماعي بالإية النسبة لعينة

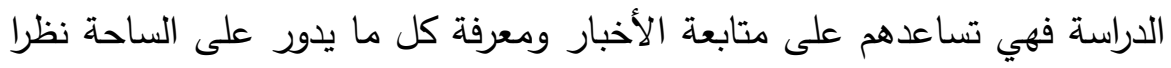

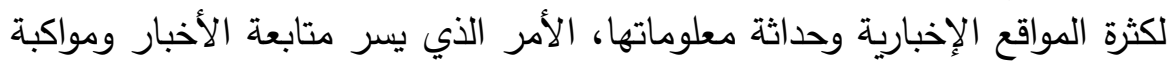

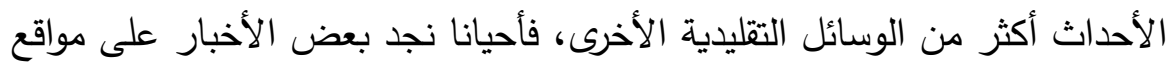

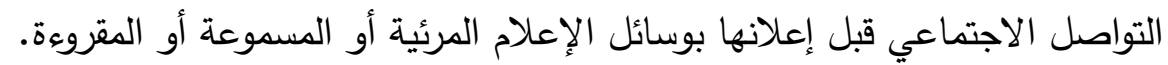


د. إيمان سيد عبد الحكيم

- يأتي في المرتبة الثانية التثقيف واكتساب المعلومات بنسبة 50,2\% من الأسباب

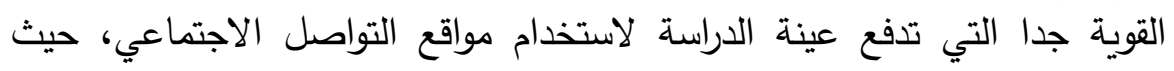

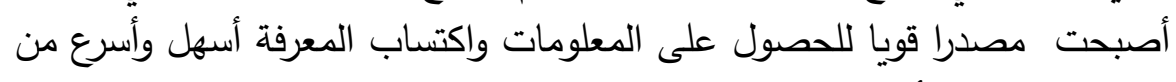
الطرق التقليدية الأخرى.

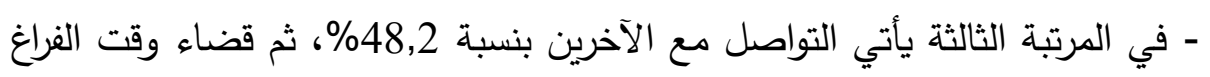

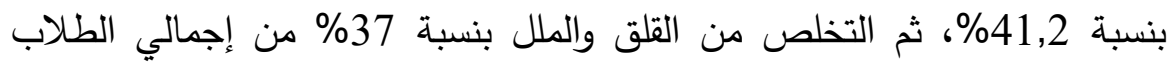

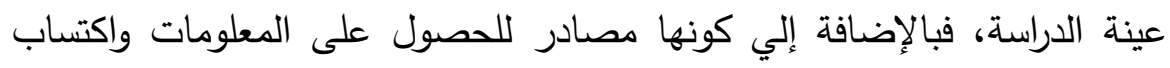
المعرفة والثقافة تعد مواقع التواصل الاجتماعي وسائل ترفيهية أيضا يتجه إلئها اليها البعض لقضاء وقت الفراغ والتخلص من القلق والملل والتواصل مع الآخرين.

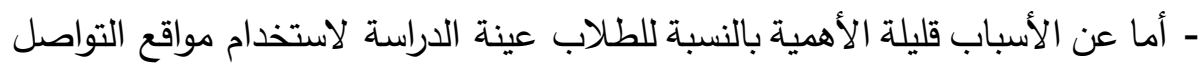
الاجتماعي جاء الهروب من الواقع بنسبة 27\% من إجمالي الطلاب عينة الدراسة.

(8) الموضوعات المفضلة لدى الطلاب عينة الدراسة عير مواقع التواصل الاجتماعي: جدول رقم (10) الموضوعات المفضلة لاى عينة الدراسة عبر مواقع التواصل الاجتماعي

\begin{tabular}{|c|c|c|}
\hline النسبة المئويةة\% & التكرار (ك) & الموضوعات \\
\hline$\% 23,2$ & 490 & 1- موضوعات شخصية \\
\hline$\% 65,9$ & 1390 & 2- موضوعات ثقافية \\
\hline$\% 15,1$ & 320 & 3- موضوعات سياسية \\
\hline$\% 46,3$ & 978 & 4- موضوعات دينية \\
\hline$\% 19,4$ & 410 & 5- موضوعات رياضية \\
\hline$\% 1,4$ & 30 & 6- موضوعات جنسية \\
\hline$\% 34,1$ & 720 & 7- موضوعات صحية \\
\hline$\% 20,3$ & 430 & 8- موضوعات فنية \\
\hline$\% 31,3$ & 660 & 9- تبادل الآراء والأفكار \\
\hline
\end{tabular}

تشير نتائج الجدول رقم (10) السابق إلي أن:

- أكثر الموضوعات المفضلة والأكثر تداولا عبر مواقع التواصل الاجتماعي لدى أفراد الدئ

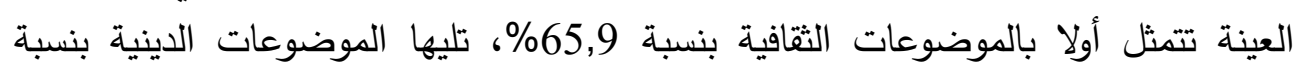

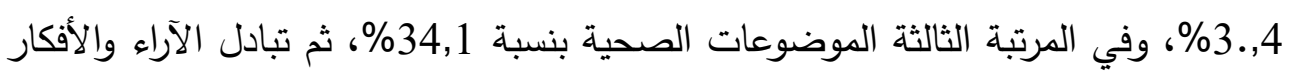
بنسبة 31,3\% من إجمالي الطلاب عينة الدراسة. 
- تشير هذه النتائج إلي وعي الطلاب عينة الدراسة نحو استخدام مواقع التواصل الاجتماعي بما ينفعه، حيث نجد أكثر الموضوعات التي يفضلون تداولها عبر مواقع التواصل الاجتماعي هي الموضوعات المهمة والمفيدة لهم، وهذا ما يتقق مع نتيجة الجدول قبل السابق رقم (9) في أن أقوى الأسباب التي تدفع عينة الدراسة لاستخدام هذه المواقع هو

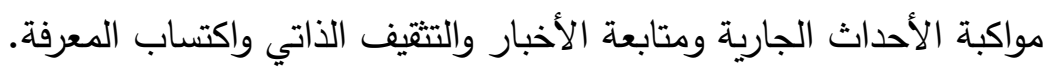

$$
\text { المحور الثالث: مخاطر مواقع التواصل الاجتماعي }
$$

(1) مدى وجود مخاطر سلبية لمواقع التواصل الاجتماعي من وحهة نظر الطلاب عينة

\section{مدى وجود مخاطر سلبية لمواقع التواصل الاجتماعي}

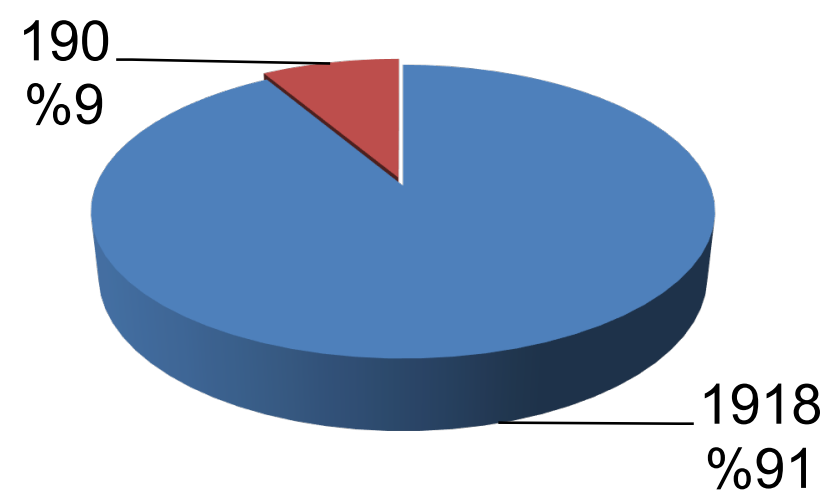

شكل رقم (4) مدى وجود مخاطر لمواقع التواصل الاجتماعي

$$
\text { من خلال الشكل السابق نتوصل إلى ما يلي: }
$$

- 91\% من إجمالي عينة الدراسة من الطلاب ترى أن هناك مخاطر لمواقع التواصل الاجتماعي، في حين نجد 9\% فقط ترى أن مواقع التواصل الاجتماعي لا خطر منها.

(2) المخاطر الاجتماعية لمواقع التواصل الاجتماعي:

يوضح الجدول التالي المخاطر الاجتماعية لمواقع التواصل الاجتماعي من وجهة

$$
\text { نظر الطلاب عينة الاراسة: }
$$

جدول رقم (11) المخاطر الاجتماعية لمواقع التواصل الاجتماعي 
د. إيمان سيد عبد الحكيم

\begin{tabular}{|c|c|c|c|c|c|c|c|c|c|c|c|c|}
\hline \multirow[t]{2}{*}{ المنوال } & \multicolumn{2}{|c|}{ غير موافق } & \multicolumn{2}{|c|}{ غير موافق } & \multicolumn{2}{|c|}{ محايد } & \multicolumn{2}{|c|}{ موافق } & \multicolumn{2}{|c|}{ موافق بثدة } & \multirow[t]{2}{*}{ المخاطر الاجتماعية } & \multirow[t]{2}{*}{ b } \\
\hline & $\%$ & العدد & $\%$ & 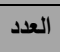 & $\%$ & العدد & $\%$ & العدد & $\%$ & العدد & & \\
\hline غير موافق & $\% 9,7$ & 205 & $\% 33,9$ & 715 & $\% 21,6$ & 456 & $\% 14,5$ & 306 & $\% \mathbf{2 0 , 3}$ & 430 & 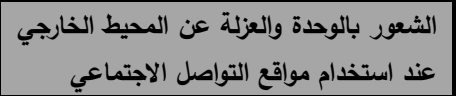 & 1 \\
\hline غير موافق & $\% 18,4$ & 389 & $\% 30,1$ & 635 & $\% 21,3$ & 450 & $\% 13,4$ & 284 & $\% 16,8$ & 355 & 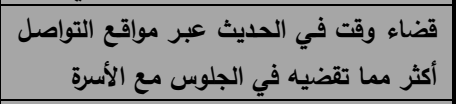 & 2 \\
\hline موافق & $\% 10,6$ & 225 & $\% 19,4$ & 410 & $\% 19,4$ & 410 & $\% 31,2$ & 658 & $\% 19,4$ & 410 & 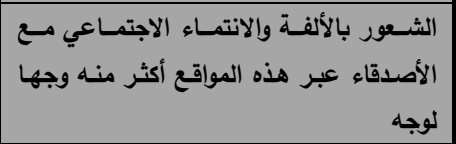 & 3 \\
\hline موافق & $\% 5,8$ & 123 & $\% 14,5$ & 306 & $\% 18,4$ & 389 & $\% 34,2$ & 723 & $\% 27,1$ & 573 & 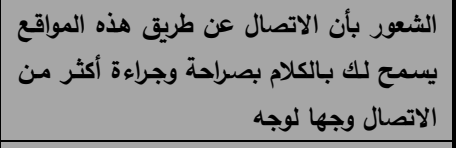 & 4 \\
\hline غير موافق & $\% 27,5$ & 580 & $\% 35,4$ & 748 & $\% 14,5$ & 306 & $\% 11,4$ & 240 & $\% 11,3$ & 240 & 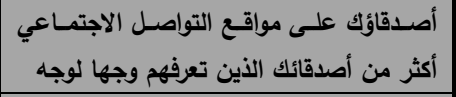 & 5 \\
\hline غير موافق & $\% \mathbf{2 0 , 4}$ & 432 & $\% 35,4$ & 748 & $\% 18,4$ & 389 & $\% 14,5$ & 306 & $\% 11,3$ & 240 & 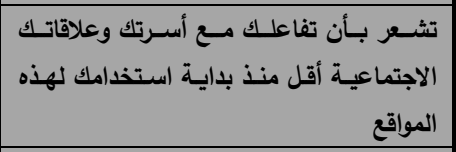 & 6 \\
\hline غير موافق & $\% \mathbf{2 0 , 4}$ & 432 & $\% 27,3$ & 576 & $\% 14,5$ & 306 & $\% 19,4$ & 410 & $\% 18,4$ & 389 & 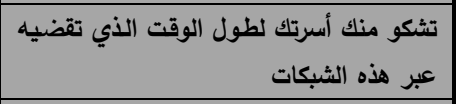 & 7 \\
\hline موافق & $\% 1,9$ & 42 & $\% 4,4$ & 93 & $\% 11,3$ & 240 & $\% 44,6$ & 941 & $\% 37,8$ & 798 & 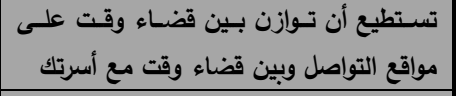 & 8 \\
\hline موافق & $\% 4,4$ & 93 & $\% 7,7$ & 163 & $\% \mathbf{2 0}, 4$ & 432 & $\% 40,4$ & 853 & $\% 27,1$ & 173 & 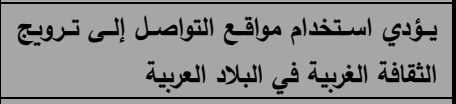 & 9 \\
\hline 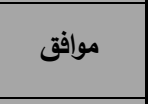 & $\% 7,7$ & 163 & $\% 14,5$ & 306 & $\% 11,3$ & 240 & $\% 35,4$ & 748 & $\% 31,1$ & 657 & 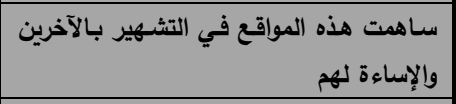 & 10 \\
\hline موافق بثدة & $\% 14,5$ & 306 & $\% \mathbf{1 4 , 5}$ & 306 & $\% 21,3$ & 450 & $\% 22,6$ & 477 & $\% 27,1$ & 573 & 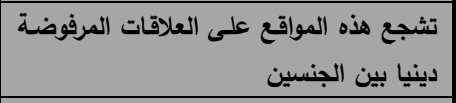 & 11 \\
\hline غير موافق & $\% 62$ & 1310 & $\% 11,3$ & 240 & $\% 7,7$ & 163 & $\% 11,3$ & 240 & $\% 7,7$ & 163 & 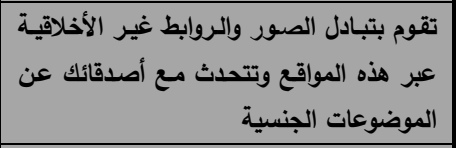 & 12 \\
\hline 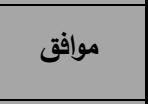 & $\% 24$ & 510 & $\% 14,5$ & 306 & $\% 11,6$ & 245 & $\% 35,4$ & 748 & $\% 14,5$ & 306 & 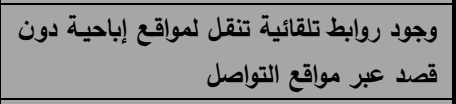 & 13 \\
\hline موافق بشدة & $\% 4,6$ & 97 & $\% 11,6$ & 245 & $\% 21,3$ & 450 & $\% 27,1$ & 573 & $\% 35,4$ & 748 & |على الحقيقة ونشر الرزيلة بين الثباب التواصل على سلأوهام & 14 \\
\hline موافق & $\% 7,7$ & 163 & $\% 11,6$ & 245 & $\% 18,4$ & 389 & $\% 35,2$ & 743 & $\% 27,1$ & 573 & 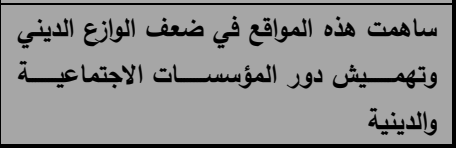 & 15 \\
\hline
\end{tabular}


من واقع دراسة نتائج الجدول السابق رقم (11)، تبين أن المخاطر الاجتماعية لمواقع

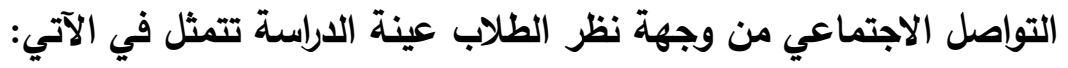

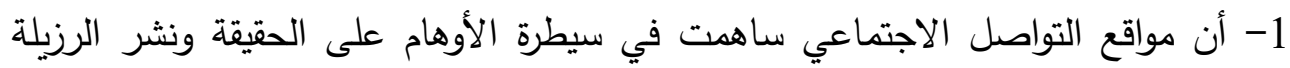

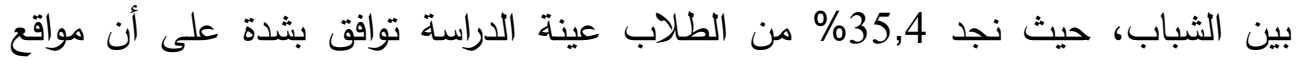

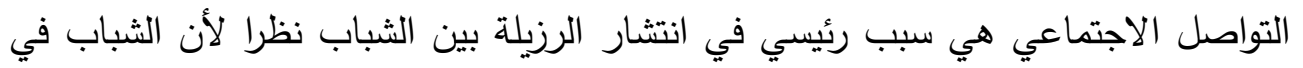
تلك المرحلة من العمر ليس لليهم الوعي الكافي للتثريق بين الأوهام والحقيقة مما يجعلهم ينجرفون خلف هذه الأوهام. 2- أن هناك 27,1\% من إجمالي عينة الدراسة توافق بثدة على أن مواقع التواصل

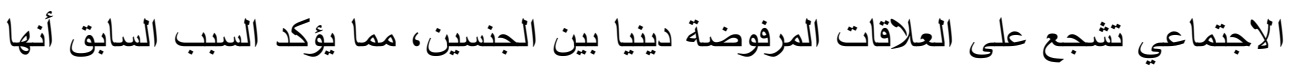
وسيلة لنشر الرزيلة بين الثباب.

3- يؤدي استخدام مواقع التواصل الاجتماعي إلى ترويج الثقافة الغريبة في البلاد العربية،

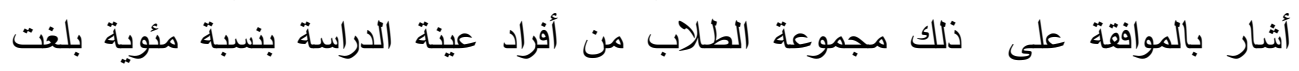

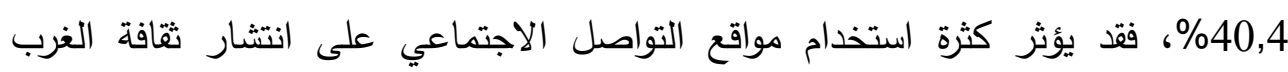
المخالفة عن عادات وتقاليد البلدان العربية مما يؤدي إلى الإضرار بالثباب ويؤئر سلبيا عليهم. 4- كذلك أشار 35,4\% من أفراد عينة الدراسة بالموافقة على أن مواقع التواصل الاجتماعي

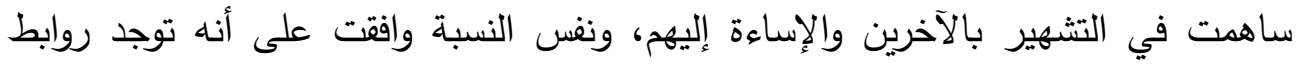

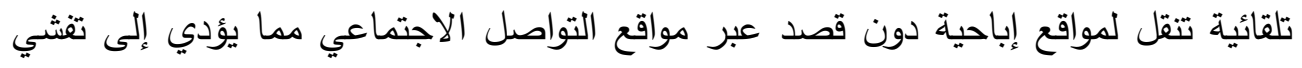
الرزيلة بين الثباب.

5- ساهمت مواقع التواصل الاجتماعي في ضعف الوازع الديني وتهميش دور المؤسسات

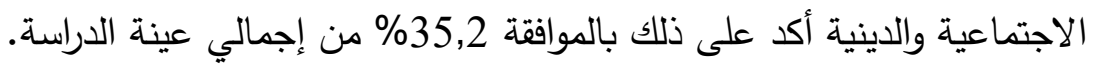

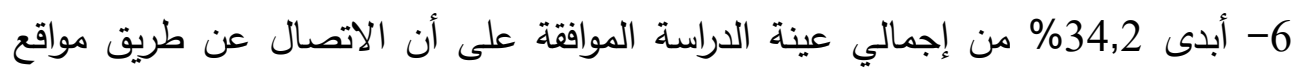

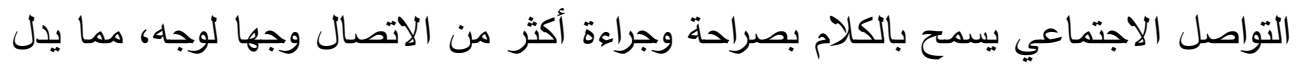

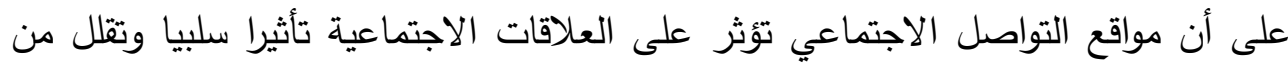

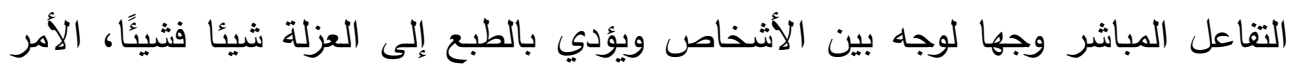

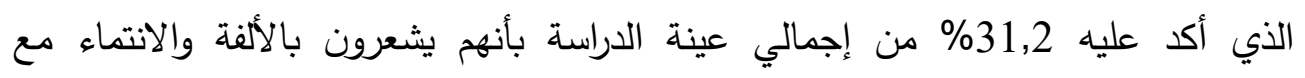
الأصدقاء عبر مواقع التواصل الاجتماعي أكثر منه وجها لوجها لونه 


\section{(3) المخاطر الأمنية لمواقع التواصل الاجتماعي:}

يوضح الجدول التالي المخاطر الأمنية لمواقع التواصل الاجتماعي من وجهة نظر

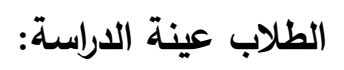

جدول رقم (12) المخاطر الأمنية لمواقع التواصل الاجتماعي

\begin{tabular}{|c|c|c|c|c|c|c|c|c|c|c|c|c|}
\hline \multirow{2}{*}{ المنوال } & \multicolumn{2}{|c|}{ غير موافق بشدة } & \multicolumn{2}{|c|}{ غيز موافق } & \multicolumn{2}{|c|}{ محايد } & \multicolumn{2}{|c|}{ موأق } & \multicolumn{2}{|c|}{ موافق بشدة } & \multirow{2}{*}{ المخاطر الأمنية } & \multirow{2}{*}{$\hat{r}$} \\
\hline & $\%$ & العدد & $\%$ & العدد & $\%$ & العدد & $\%$ & العدد & $\%$ & العدد & & \\
\hline 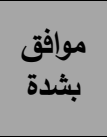 & $\% 21,3$ & 450 & $\% 25,2$ & 533 & $\% 8,7$ & 185 & $\% 17,5$ & 370 & $\% 27,5$ & 580 & 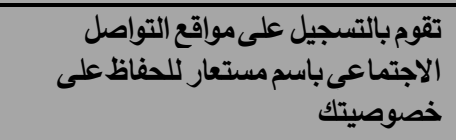 & 1 \\
\hline غوافير & $\% 18,4$ & 389 & $\% 40,4$ & 853 & $\% 18,4$ & 389 & $\% 16,8$ & 355 & $\% 6$ & 130 & تذه المواقع خوفا من الريث كثرا مالأصدة الأمنية عبر & 2 \\
\hline موافق & - & - & $\% 6,5$ & 139 & $\% 16,7$ & 353 & $\% 44,6$ & 941 & $\% 32,2$ & 680 & وانحرافت المجتمع المواقع في زيادة الجرائم & 3 \\
\hline موافق & $\% 2,9$ & 63 & $\% 4,6$ & 99 & $\% 18,4$ & 389 & $\% 44,6$ & 941 & $\% 29,5$ & 622 & خصوصية أن هذه المواقع تتيع خرق & 4 \\
\hline موافق & $\% 2,1$ & 45 & $\% 7,7$ & 163 & $\% 31,1$ & 657 & $\% 35,4$ & 748 & $\% 23,7$ & 500 & تساهم هذه الهواقع في تأصبيل القيم & 5 \\
\hline بشدة موافق & $\% 0,9$ & 19 & $\% 0,9$ & 19 & $\% 16,8$ & 355 & $\% 27,1$ & 573 & $\% 54,3$ & 1145 & 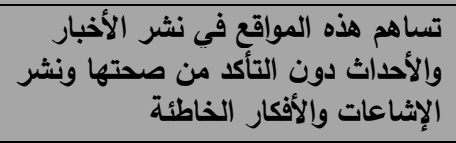 & 6 \\
\hline موافت & $\% 3,3$ & 70 & $\% 5,8$ & 123 & $\% 27,5$ & 580 & $\% 31,2$ & 658 & $\% 32,2$ & 680 & لهذه المواقع دور في التحريض & 7 \\
\hline موافق & - & - & $\% 6$ & 130 & $\% 10,6$ & 225 & $\% 38,8$ & 820 & $\% 44,6$ & 941 & تعاهمت فذه المواقع من أهم الأدوات التي & 8 \\
\hline موافق & $\% 1,9$ & 42 & $\% 2,9$ & 63 & $\% 9,8$ & 208 & $\% 38,8$ & 820 & $\% 46,6$ & 984 & لهذه المواقع تأثيرا فكريا على & 9 \\
\hline محايد & $\% 2,1$ & 45 & $\% 4,6$ & 99 & $\% 37,4$ & 790 & $\% 23,7$ & 500 & $\% 32,2$ & 680 & شزعزعة الوحدة الوطواقع على إثارة الفتن & 10 \\
\hline موافق & $\% 1,6$ & 34 & $\% 5,8$ & 123 & $\% 32,2$ & 680 & $\% 37,8$ & 797 & $\% 22,6$ & 477 & تضاهمت هذيقل الدأهداث المواقع في نقل الصارية فى ظل الصورة & 11 \\
\hline موافق & $\% 3,9$ & 83 & $\% 12,6$ & 267 & $\% 23,7$ & 500 & $\% 40,4$ & 853 & $\% 19,4$ & 410 & تعتبر هذه المواقع وسيلة لترويتج أفكار & 12 \\
\hline بشدة & $\% 2,9$ & 63 & $\% 2,9$ & 63 & $\% 8,9$ & 189 & $\% 18,4$ & 389 & $\% 66,9$ & 1412 & هوناك خطورة في نشر الصور الثولع الثخية & 13 \\
\hline موافق & $\% 7,7$ & 163 & $\% 11,6$ & 245 & $\% 22,6$ & 477 & $\% 35,4$ & 748 & $\% 22,7$ & 478 & 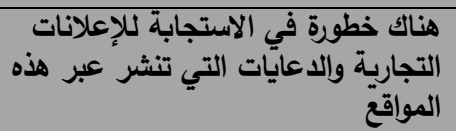 & 14 \\
\hline
\end{tabular}


بدراسة نتائج الجدول السابق رقم (12) يمكن الاطلاع على المخاطر الأمنية لمواقع التواصل الاجتماعي من وجهة نظر الطلاب من أفراد عينة الدارسة:

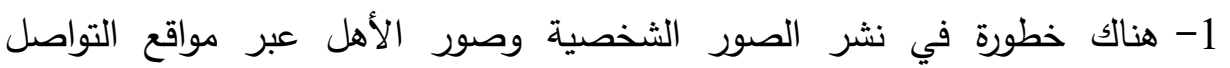

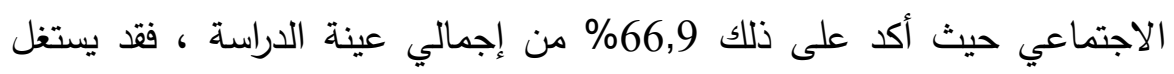

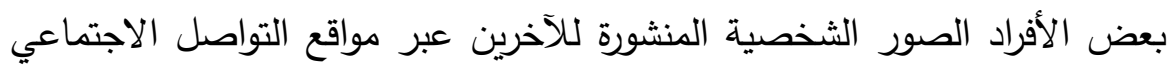
استغلالا سيئا مما يضر بهؤلاء الأشخاص أمنيا واجتماعيا.

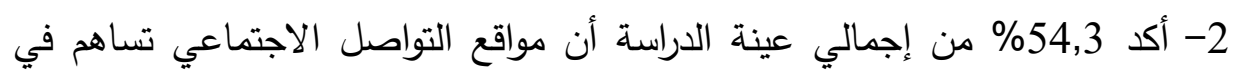

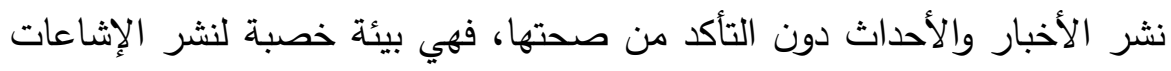
والأفكار الخاطئة التي سرعان ما يندفع الثباب نحوها.

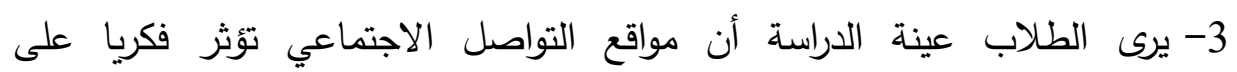

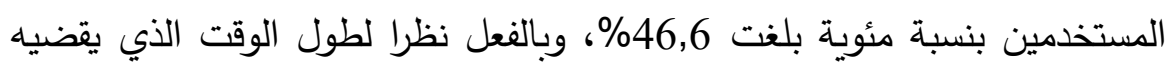

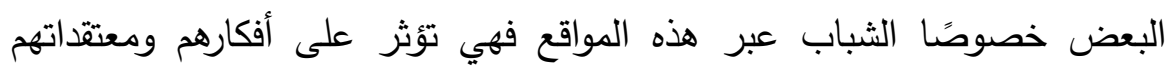

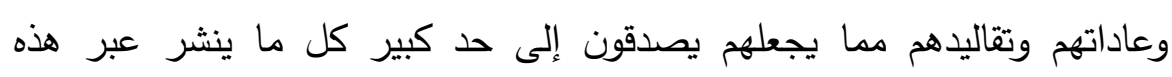
المواقع حتي وإن كان مخالفا لعرفهم وتقاليدهم.

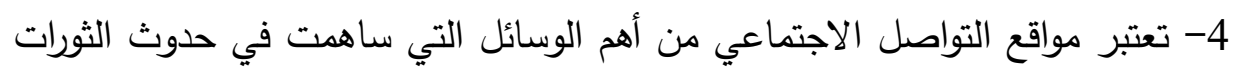

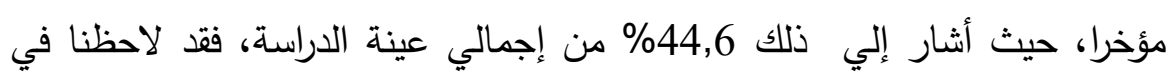

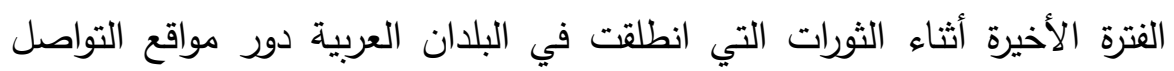

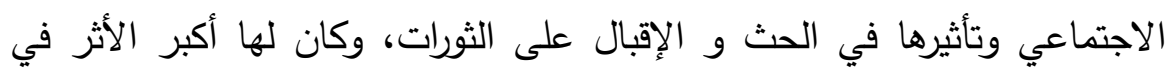

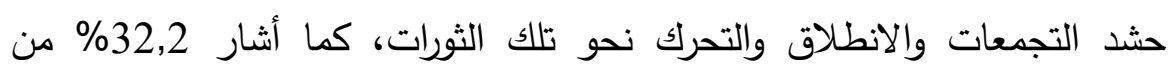
إجمالي عينة الدراسة أن لتلك المواقع دورًا في التحريض على على الإنى الاعتصام

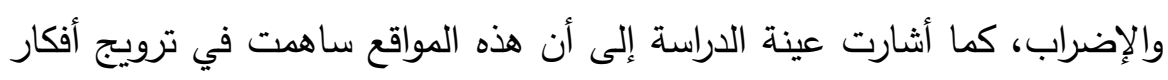

$$
\text { وآراء ومخططات الجماعات الإرهابية المتطرفة. }
$$

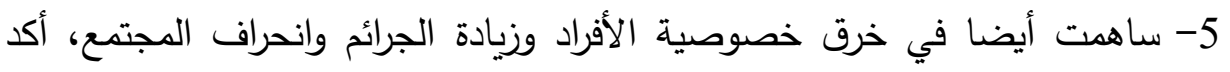

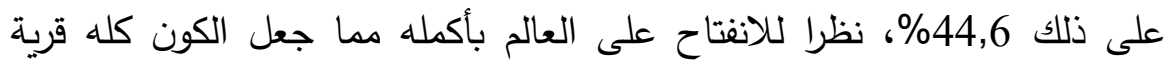

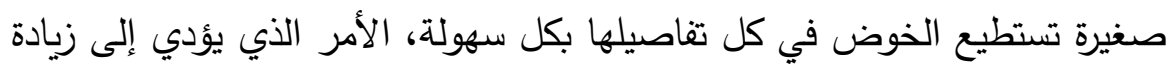
الجرائم والانحراف وتأصيل القيم الهدامة والغربية في المجتمعات العربية. 
(4) مقترحات تقليل مخاطر مواقع التواصل الاجتماعي من وجهة نظر الطلاب عينة

الاراسية:

يبين الجدول التالي مقترحات الطلاب من أفراد عينة الدراسة حول تقليل مخاطر مواقع التواصل الاجتماعي: جدول رقم (13) مقترحات تقليل مخاطر مواقع التواصل الاجتماعي

\begin{tabular}{|c|c|c|c|}
\hline النسبة المئوية \% & التكرار (ك) & المقترحات & 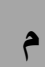 \\
\hline$\% 52,4$ & 1106 & التقييد بالقيم الاينية عند استخدام هذه & 1 \\
\hline$\% 33$ & 699 & إستخدام الملف الثخصية بطريقة & 2 \\
\hline$\% 33,9$ & 715 & علتم التعدي على حدود الآخرين في & 3 \\
\hline$\% 31$ & 655 & والتعرام الآخرين في الإدلاء بالرأي & 4 \\
\hline$\% 23,3$ & 493 & تجنب الإفراط في استخدام هذه الوسائل & 5 \\
\hline$\% 23,3$ & 493 & لقائمة أصدق الجيد لمن يريد إضافة اسمه & 6 \\
\hline$\% 26,5$ & 560 & الانتباه الكامل عند نشر البيانات & 7 \\
\hline
\end{tabular}

بدراسة واقع المقترحات المقدمة من الطلاب عينة الدارسة لتقليل مخاطر مواقع التواصل الاجتماعي يتبين الآتي:

1- التقيد بالقيم الدينية عند استخدام مواقع التواصل الاجتماعي حصل على المرتبة الأولى الألي من مقترحات عينة الدراسة بنسبة بلغت 52,4\% من إجمالي العينة، فربما يكون الوازع الديني هو الجدار الحامي من مساوئ ومخاطر مواقع التواصل الاجتماعي. 
2- في المرتبة الثانية جاء عدم التعدي على حقوق الآخرين في التفاعلات بنسبة

$$
\text { \%33,9 من إجمالي عينة الدراسة. }
$$

3- جاء استخدام الملف الثخصي بطريقة إيجابية وتبادل المعلومات المناسبة في الرتبة الثالثة بنسبة مئوية بلغت 33\% من إجمالي عينة الدراسة، فقد تكون من أكثر

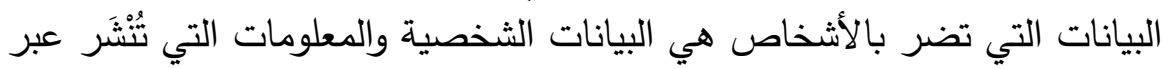

$$
\text { هذه المواقع. }
$$

4- يأتي في المرتبة الرابعة احترام الآخرين في الإدلاء بالرأي والتعليقات بنسبة بلغت

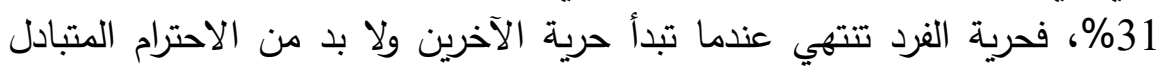

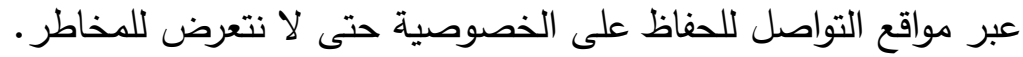

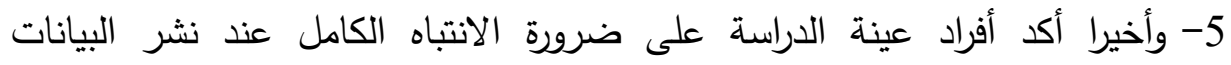
الشخصية والفحص الجيد عند إضافة الأصدقاء، وكذلك تجنب الإفراط في استخدام مواقع التواصل الاجتماعي.

\section{نتائج الارباسة:}

هدفت الاراسة إلى التعرف على المخاطر الأمنية والاجتماعية لمواقع التواصل

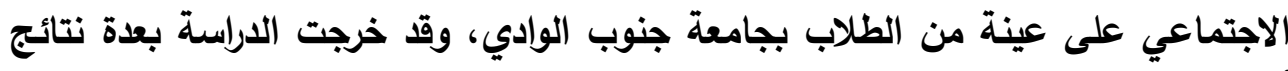

1- أثارت نتائج الدراسة إلى أن أكثر مواقع التواصل الاجتماعي استخداما من قبل

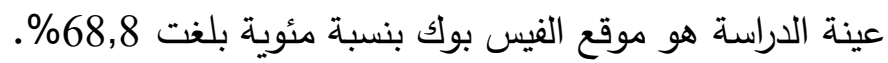

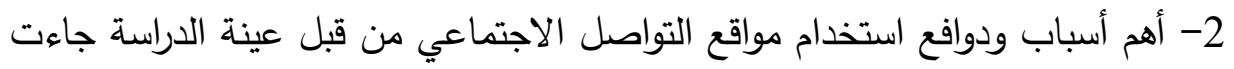

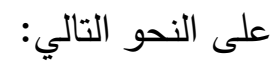
- في المرتبة الأولي: مواكبة الأحداث الجارية ومتابعة الأخبار بنسبة بلغت 60,2\%

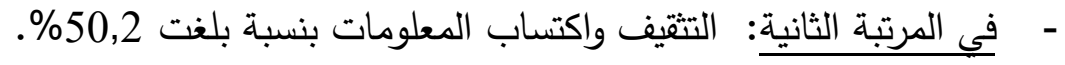

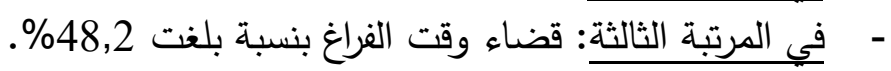

3- جاءت أكثر الموضوعات تداولا عبر مواقع التواصل الاجتماعي من قبل فيل عينة الدراسة أولا الموضوعات الثقافية بنسبة 65,9\%، تليها الموضوعات الداتينية بنسبة

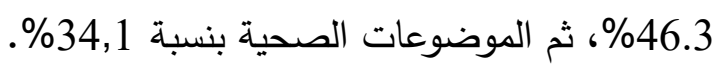

4- توصلت الدراسة إلى أن أكثر المخاطر الاجتماعية لمواقع التواصل الاجتماعي من المن وجهة نظر الطلاب عينة الدراسة تتلخص في الآتي: 
د. إيمان سيد عبد الحكيم

- - سيطرة الأوهام على الحقيقة ونشر الرزيلة بين الشباب بنسبة بلغت 35,4\% .

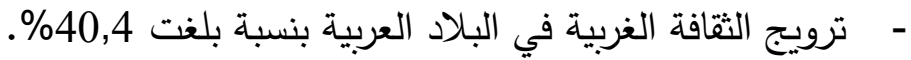

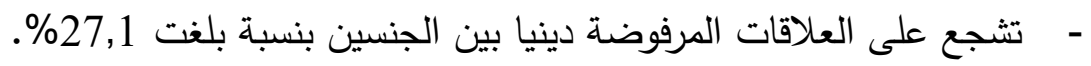

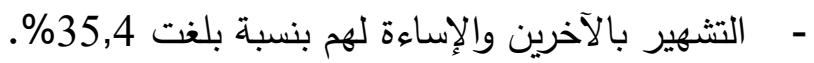

- - ضعف الوازع الديني وتهميش دور المؤسسات الدينية والاجتماعية 35,2\%

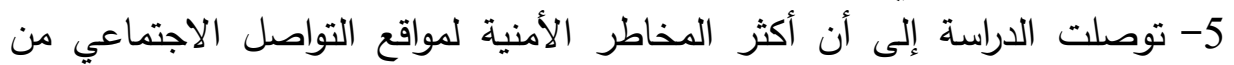
وجهة نظر الطلاب عينة الدراسة تتلخص في الآتي: - خطورة نشر الصور الثخصية وصور الأهل عبر مواقع التواصل الاجتماعي بنسبة بلغت 66,9\%.

- - نشر الأخبار والأحداث دون التأكد من صحتها بنسبة بلغت 54,3\% .

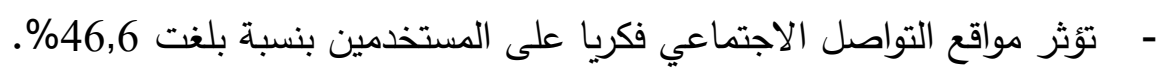

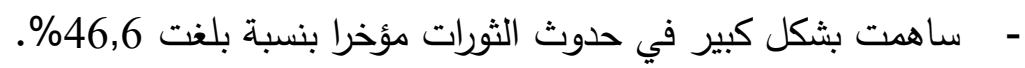

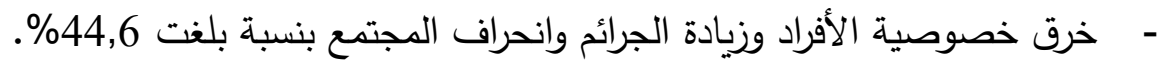
- التحريض على الاعتصام والإضراب بنسبة بلغت 32,2\%

\section{توصيات الاراسة:}

1- توعية فئات المجتمع عامة وطلاب الجامعة خاصة بالآثار الإيجابية والسلبية لمواقع التواصل الاجتماعي من خلال وسائل الإعلام.

2- ضرورة التوعية من قبل الجامعة من خلال مقرر دراسي وعقد دورات توعوية بأهمية

مواقع التواصل الاجتماعي وكيفية الاستخدام الأمثل لها والتوعية بمخاطرها. 3- نشر ثقافة الرقابة الذاتية من خلال مواقع التواصل الاجتماعي وتعزيز الوازع الديني لاي الثباب. 4- وضع قواعد وضوابط من خلال الوسائل التكنولوجية الحديثة لمراقبة المواقع الممنوعة والتوعية بالاستخدام الرشيد المعتدل لمواقع التواصل الاجتماعي.

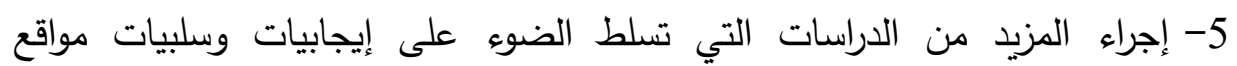
التواصل الاجتماعي وأهميتها. 
المصادر العربية والأحنبية:

(1) إسماعيل، محمود حسن (2003). مبادئ علم الاتصال ونظريات التأثير.__القاهرة: الدار العالمية للنشر والتوزيع.

(2) بوسحلة، مفيدة وطهوري، نبيل (2014). الثبكات الاجتماعية وأثرها على العلاقات الاجتماعية لدى الطلبة (الفيس بوك وتويتر نموذجا)._ المجلات الاجتماعية التقليدية والحديثة وإنتاج الهوية الفردية والجماعية في المجتمع الجزائري.-- جامعة قاصدي مرباح:

$$
\text { قسم علم الاجتماع والديموغرافيا. }
$$

(3) الجبول، خالد منيزل عبدالله (2016). المخاطر الأمنية والاجتماعية لشبكات التواصل الاجتماعي على الثباب الأردني من وجهة نظر طلبة الجامعات الأردنية._ جامعة مؤته.ـ

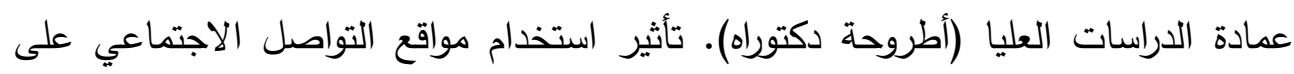
التحصيل الدراسي في كلية علوم الحاسوب والرياضيات. _ _ جامعة القادسية._ كلية علوم الحاسوب والرياضيات: قسم الإحصاء المعلوماتية. (4) شناوي، سامي أحمد وعباس، محمد خليل (2014). استخدام شبكة التواصل الاجتماعي (الفيس بوك) وعلاقته بالتوافق النفسي لدي المراهقيـن._ جامعـة عمان العربية.ـ

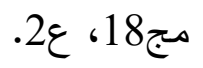
(5) الثهري، حنان بنت شعشوع (1434هـ). أثر استخدام شبكات التواصل الإلكترونية على

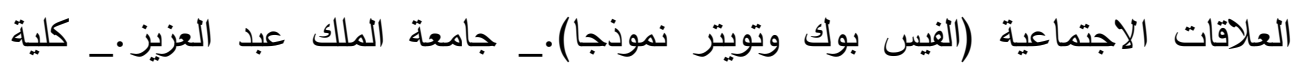
الآداب والعلوم الإنسانية: قسم الاجتماع (أطروحة ماجستير ).

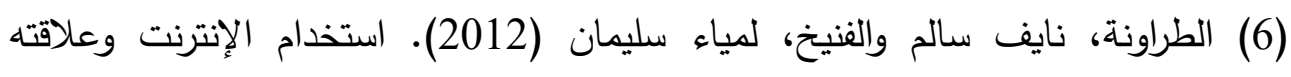
بالتحصيل الأكاديمي والتكيف الاجتماعي والاكتئاب ومهارات الاتصال لدي طلبة جامعة

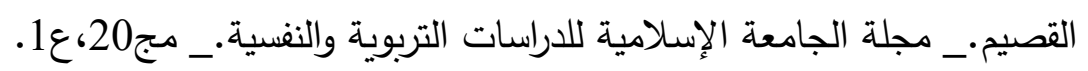
(7) عبد الرؤوف، سامي (2000). الإنترنت في العالم العربي: دراسة ميدانية على عينة من

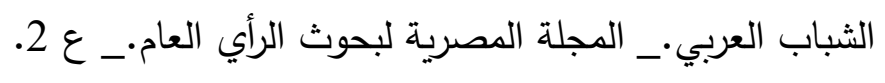


(8) عبد المنعم، محمد محمد والطاهر ، الرشيد إسماعيل وغريب، زينب عبد الرؤوف. أثر استخدام شبكات التواصل الاجتماعي على مهارات التواصل والثعور بالوحدة النفسية لدي طلبة جامعة الملك فيصل.

(9) عرقوب، إبراهيم والخدام، حمزة خليل (2012). تأثير الإنترنت على الاتصال الثخصي بالأسرة والأصدقاء: دراسة ميدانية._ مجلة دراسات العلوم الإنسانية والاجتماعية.ــ مج الإنترني .2 ع 39

(10) عوض، رشا أديب (2014). آثار استخدام مواقع التواصل الاجتماعي على التحصيل الدراسي للأبناء في محافظة طولكرم من وجهة نظر ربات البيوت. جامعة القدس._كلية التتمية الاجتماعية: تخصص خدمة اجتماعية. (11) غزال، مريم وشعوبي، نور الهدى (2014). تأثير مواقع التواصل الاجتماعي على تتمية الوعي السياسي لدي الطلبة الجامعيين. جامعة قاصدي مرباح.-- كلية العلوم الإنسانية والاجتماعية: قسم العلوم الإنسانية. (12) الماس، محمود حسن (2016) جهود المملكة العربية السعودية نحو مكافحة بعض الإن مواقع شبكات الإنترنت لحماية الأمن الوطني.- جامعة القاهرة._ كلية الآداب: قسم المكتبات والوثائق وتقنية المعلومات. (أطروحة ماجستير ) (13) المتبولي، هبة محمد (2015). إفادة طلاب الجامعات من الشبكات الاجتماعية على ونى الإنترنت كمصدر للمعلومات: دراسة ميدانية على طلاب جامعة طنطا.-- جامعة طنطا.ـ كلية الآداب: قسم المكتبات والمعلومات.(أطروحة دكتوراه) (14) نومار، مريم نريمان (2012). استخدام مواقع الشبكات الاجتماعية وتأثيره في

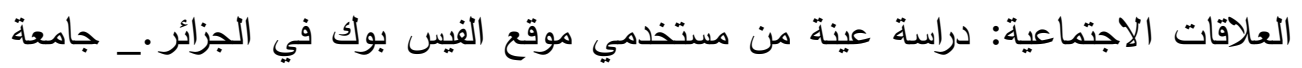
الحاج لخضر باتنه._كلية العلوم الإنسانية: قسم علوم الإعلام.(أطروحة ماجستير). (15) Soebhektie, Sabrina(2016). A Risk Analysis of Social Networking Services for a Small Enterprise: A Case Study of Conclave. Laurea University of Applied Sciences.

(16) Gunther Eysenbach(2017). Internet Use and Access, Behavior, Cyberbullying, and Grooming: Results of an Investigative Whole City Survey of Adolescents. Interact J Med Res. Jul-Dec; 6(2): e9. 
الخخاطر الاجتماعية والأمنية لمواقع التو اصل الاجتماعي على عينة من الطلاب بجامعة جنوب الو ادي بقنا

(17) Louis Leung (2014). Predicting Internet risks: a longitudinal panel study of gratifications-sought, Internet addiction symptoms, and social media use among children and adolescents. Health Psychol Behav Med. 2014 Jan 1; 2(1).

(18) Candid Wüest. The Risks of Social Networking. Senior Software Engineer.

(19) Hoon Jung Koo \& Jung-Hye Kwon(2014). Risk and Protective Factors of Internet Addiction: A Meta-Analysis of Empirical Studies in Korea. Yonsei Med J. 2014 Nov 1; 55(6). 